\title{
Accumulation of Exogenous Amyloid-Beta Peptide in Hippocampal Mitochondria Causes Their Dysfunction: A Protective Role for Melatonin
}

\author{
Sergio Rosales-Corral, ${ }^{1,2}$ Dario Acuna-Castroviejo, ${ }^{3}$ Dun Xian Tan, ${ }^{2}$ \\ Gabriela López-Armas, ${ }^{1}$ José Cruz-Ramos, ${ }^{1}$ Rubén Munoz, ${ }^{4}$ Valery G. Melnikov, ${ }^{5}$ \\ Lucien C. Manchester, ${ }^{2}$ and Russel J. Reiter ${ }^{2}$ \\ ${ }^{1}$ Centro de Investigación Biomédica de Occidente del Instituto Mexicano del Seguro Social, Sierra Mojada 800 Colonia Independencia, \\ 44340 Guadalajara, JAL, Mexico \\ ${ }^{2}$ Department of Cellular and Structural Biology, The University of Texas Health Science Center at San Antonio, 7703 Floyd Curl Drive, \\ San Antonio, TX 78229-3900, USA \\ ${ }^{3}$ Institute of Biotechnology, Biomedical Research Center, Health Sciences Technology Park, University of Granada, \\ Avda. del Conocimiento s/n, 18100 Armilla, Granada, Spain \\ ${ }^{4}$ Centro de Ciencias Exactas e Ingenieria de la Universidad de Guadalajara, Blvd. Marcelino García Barragán \#1421, \\ CP 44100, Guadalajara, JAL, Mexico \\ ${ }^{5}$ University Center for Biomedical Research Center, University of Av. Universidad \#333. Colonia Las Víboras. CP 28040, \\ Colima, Col, Mexico
}

Correspondence should be addressed to Sergio Rosales-Corral, rosalescorra@uthscsa.edu

Received 14 October 2011; Accepted 12 January 2012

Academic Editor: Daniel Pens Gelain

Copyright (C) 2012 Sergio Rosales-Corral et al. This is an open access article distributed under the Creative Commons Attribution License, which permits unrestricted use, distribution, and reproduction in any medium, provided the original work is properly cited.

\begin{abstract}
Amyloid-beta $(\mathrm{A} \beta)$ pathology is related to mitochondrial dysfunction accompanied by energy reduction and an elevated production of reactive oxygen species (ROS). Monomers and oligomers of $\mathrm{A} \beta$ have been found inside mitochondria where they accumulate in a time-dependent manner as demonstrated in transgenic mice and in Alzheimer's disease (AD) brain. We hypothesize that the internalization of extracellular $\mathrm{A} \beta$ aggregates is the major cause of mitochondrial damage and here we report that following the injection of fibrillar $\mathrm{A} \beta$ into the hippocampus, there is severe axonal damage which is accompanied by the entrance of $A \beta$ into the cell. Thereafter, $A \beta$ appears in mitochondria where it is linked to alterations in the ionic gradient across the inner mitochondrial membrane. This effect is accompanied by disruption of subcellular structure, oxidative stress, and a significant reduction in both the respiratory control ratio and in the hydrolytic activity of ATPase. Orally administrated melatonin reduced oxidative stress, improved the mitochondrial respiratory control ratio, and ameliorated the energy imbalance.
\end{abstract}

\section{Introduction}

The intracellular accumulation of highly amyloidogenic $1-42$ residue amyloid-beta peptide $\left(\mathrm{A} \beta_{1-42}\right)$ may result from, (a) decreased $\mathrm{A} \beta$ degradation due to disruption of the ubiquitinproteasome system, (b) increased intracellular generation of $\mathrm{A} \beta$, or (c) increased uptake of $\mathrm{A} \beta$ from an external source $[1$, $2]$. The internalization of $A \beta_{1-42}$ peptide by primary neurons is related to a lipid raft-mediated endocytosis [2]. These lipid rafts are dynamic assemblies of proteins and lipids floating freely within the liquid-disordered bilayer of cellular membranes where cholesterol and sphingomyelin play key roles [3]. Reciprocally, cholesterol and sphingomyelin metabolism are strongly related to $\mathrm{A} \beta[4]$. In fact, there are clues indicating that $\mathrm{A} \beta$ levels change in response to blood cholesterol content, while the clinical progression of Alzheimer's disease (AD) is commonly associated to hypercholesterolemia and high cholesterol levels in the brain $[5,6]$.

Another factor gaining more relevance as a mechanism of neuronal damage is oxidative stress, which is a hallmark 
feature of $\mathrm{A} \beta$-induced brain damage in $\mathrm{AD}$ [7], $\mathrm{AD}$ transgenic mice [8], as well as in in vitro and other in vivo models of this neurodegenerative condition $[9,10]$. Mitochondrial dysfunction and associated oxidant stress have been linked to numerous complex diseases and aging $[11,12]$, such association has been largely established by in vitro determination of mitochondrial free radicals overproduction. Membraneassociated oxidative stress in turn has been linked to lipid alterations [13], and the exposure of hippocampal neurons to $\mathrm{A} \beta$, in vitro, induces oxidative damage to membranes, accompanied by accumulation of sphingomyelin-derived ceramide species and cholesterol [14]. In fact, by preventing the accumulation of ceramides and cholesterol it is possible to protect neurons from death induced by $\mathrm{A} \beta$; this is achieved with an antioxidant like $\alpha$-tocopherol or by depleting hippocampal neurons of its sphingomyelin content with an inhibitor of serine palmitoyltransferase, the rate-limiting step in sphingolipid synthesis [15]. Focal demyelination of the cortical grey matter as well as of dystrophic neurites has been observed in $\mathrm{AD}$ patients and transgenic mice associated to $A \beta$ plaque core [16]. Thus, it is possible that the breakdown of myelin promotes the buildup of toxic $A \beta$ fibrils, which eventually accumulate in the brain [17].

There is evidence, on the other hand, that the amyloid precursor protein (APP) and $\mathrm{A} \beta$ accumulate in mitochondrial membranes, as observed in postmortem $\mathrm{AD}$ or in transgenic mice brain sections [18-20]. A $\beta$ extracellularly applied to human neuroblastoma SH-SY5Y cells was found to be internalized and be taken up by mitochondria by using the transporter outer membrane (TOM) [21]. Most of the imported $\mathrm{A} \beta_{1-42}$ appeared associated to the inner membrane and only a small fraction was localized to the matrix.

We hypothesized that due to its amphipathic nature [22], its physicochemical composition [23], and being aided by oxidative stress $[10,24], \mathrm{A} \beta$ paves its own pathway from extracellular space to mitochondria where it disrupts membrane fluidity and causes energetic dysfunction. This mechanism of membrane permeabilization induced by $A \beta$ and its own internalization might be the major cause of mitochondrial dysfunction.

Since oxidative stress is considered a key factor in these pathogenic mechanisms, melatonin should reduce the dysfunctional manifestations of $\mathrm{A} \beta$ uptake [25]. Melatonin is a proven antioxidant $[26,27]$, especially in the brain where it reduces molecular damage as demonstrated in animal models of $\mathrm{AD}[28,29]$, as well as in other experimental models of neurodegeneration [30-33]. There are two important clues regarding the role of melatonin in mitochondria rescue, (1) melatonin penetrates mitochondria where it scavenges free radicals [34, 35], (2) melatonin directly inhibits mitochondrial permeability transition pore (MtPTP) [36].

To further document these potential protective effects of melatonin, we worked in vivo by injecting fibrillar $\mathrm{A} \beta_{1-42}$ directly into hippocampal CA1 pyramidal neurons layer. Aged Wistar rats used in these experiments had no other condition or genetic predisposition to form plaques or other $\mathrm{AD}$ features.

\section{Results}

2.1. Axonal Damage in $f A \beta$ Injected Rats. The most striking abnormal change was the intramural accumulation, adhesion, and formation of $A \beta$ aggregates in the myelinated axons. Thus, $A \beta$ invaded the concentric multilamellar myelin sheath of the axon (oligodendrocyte cytoplasm). These $\mathrm{A} \beta$ aggregates caused dissection and disruption of myelin layers with mural vacuolization, forming onion bulb-like protuberances as found in chronic neuropathies [37]. In some cases, all layers were disrupted and positive $A \beta-$ immunoreactivity extending from the interstitium to the axonal lumen was observed (Figure 1). Within the onion bulb-like protuberances, $A \beta$ appeared to form aggregates; once inside the axons and mitochondria, the $\mathrm{A} \beta$ aggregates were disintegrated, adopting a granular appearance.

\subsection{Cholesterol-Enriched Diet in A $\beta$-Injected Rats Is Related to a Significant Increase in Mitochondrial Membrane Damage. Animals fed with regular Laboratory Rodent Diet showed a normal cholesterol level in blood. When these animals were intracerebrally injected with $\mathrm{A} \beta$ showed not only significantly less degree of mitochondrial structural damage as compared to $\mathrm{A} \beta$-injected but also hypercholesterolemic animals due to a cholesterol-enriched diet, as observed by electron microscopy (Figure 2).}

\subsection{Intracerebrally Injected $f A \beta_{1-42}$ Causes Extracellular} Aggregates, Axonal Degeneration, and Accumulates in Mitochondria. Thirty-six hours following the intracerebral injection of $\mathrm{f} \mathrm{A} \beta_{1-42}$, brain tissue was obtained and subjected to conventional and transmission electron microscopic examination. Using a polyclonal antibody against $A \beta$ for immunohistochemistry, extracellular deposits of this peptide accompanied by an intense microglial response (data not shown) were revealed, as expected (Figure 3(a)). 70-90 nm ultrathin brain sections were incubated with the same anti$\mathrm{A} \beta$ primary antibody, followed by incubation with a goldlabeled secondary antibody. The observation by electron microscopy revealed $\mathrm{A} \beta$ immunoreactivity inside mitochondria (Figure 3(b)), accompanied by important swelling, rupture of the outer membrane and cristae dissolution (Figures $3(\mathrm{~b})$ and $3(\mathrm{c})$ ). $\mathrm{A} \beta$ was found localized to the cristae of the inner membrane of mitochondria. Both in $\mathrm{H}_{2} \mathrm{O}_{2}$ - and in $\mathrm{fA} \beta$-injected brains significant ultrastructural alterations were observed. $\mathrm{H}_{2} \mathrm{O}_{2}$ was chosen as a positive control of oxidative stress, because of its well-known pathogenic relationship with $\mathrm{A} \beta$ (reviewed in [38]). The most prominent change was the peripheral vacuolization of the cristae, as shown in Figure 3. Vacuolization in mitochondria was accompanied by electrodense $A \beta$-immunoreactivity with inclusions being grouped and bound to the membranes, particularly to the inner cristae membranes. Rupture of the membranes resulted in discontinuity and formation of gaps. Mitochondria looked swollen with disorganized membrane structures and the cristae were lost. In some localized areas, the intermembranous space was absent and the mitochondrion appeared like an irregularly enlarged, single-membrane sac (Figure 3(c)). 


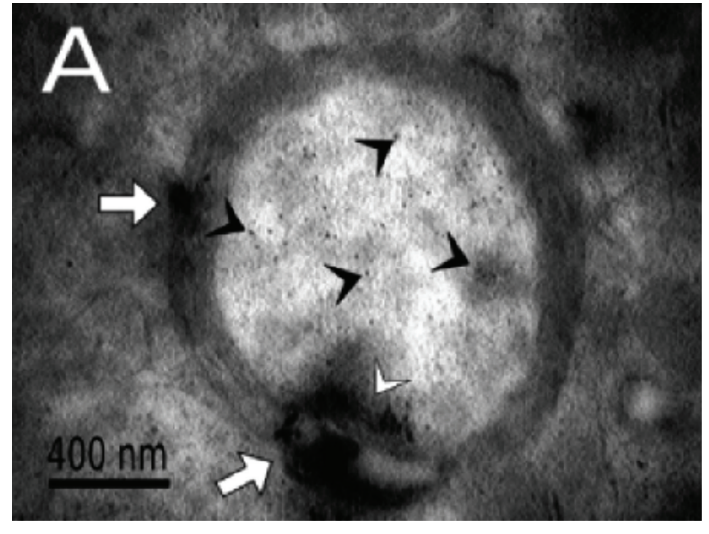

(a)

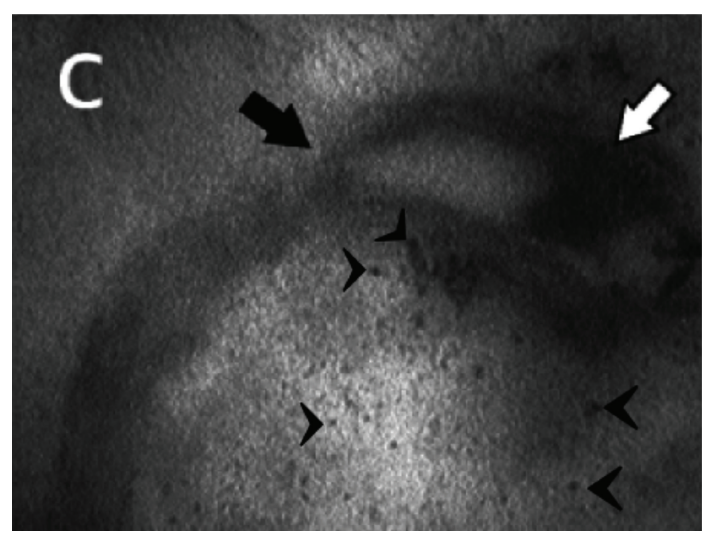

(c)

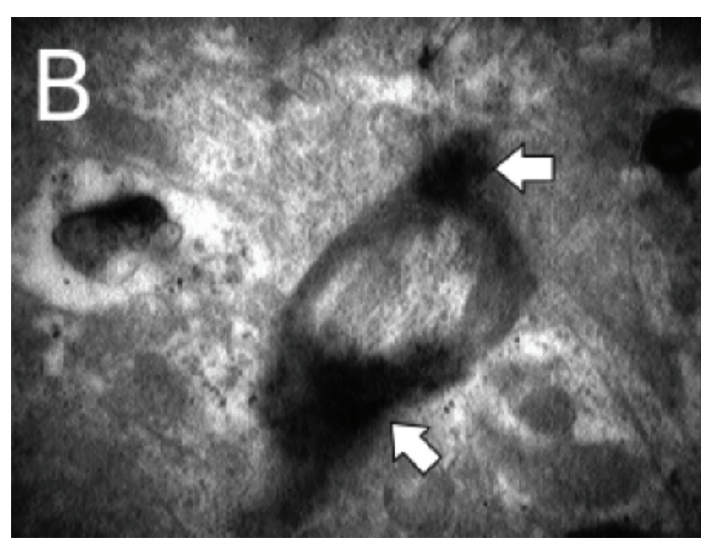

(b)

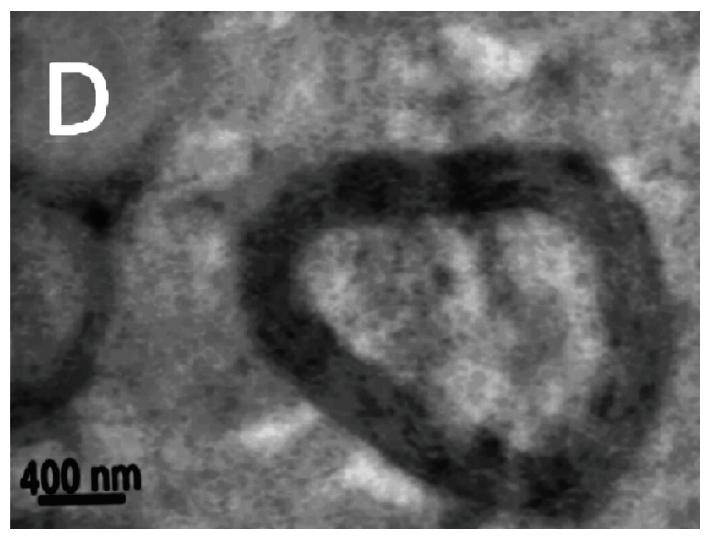

(d)

FIGURE 1: $A \beta$-induced axonal damage. Following the intracerebral injection of $\mathrm{fA} \beta$ into the hippocampus, small blocks of tissue brain containing the lesion area were postfixed in osmium tetroxide $2 \%$, embedded for 48 hours in Embed 812 , cut into $70-90$ nm ultrathin sections, and then subjected to immunohistochemical procedures using an anti-A $\beta$ antibody. Binding sites of the primary antibody were then revealed by incubating with a gold-labeled secondary antibody. Finally, sections were counterstained with uranyl acetate and lead citrate and observed in an electron microscope. (a) Amyloid tangles within the concentric layers of myelin sheath of axons (white arrows) and a widening of the myelin sheath, corresponding to accumulations of $\mathrm{A} \beta$ from a primary pole, are observed. Electrodense spots sparse within the axon (black arrowheads), also seem to enter into the lumen from the primary pole (white arrowhead) (16,700x). (b) A $\beta$ electrodense spots penetrating into the axons from widening onion bulb-like structures (white arrows) (10,000x). (c) Onion bulb detail (35,750x) showing abundant electrodense material corresponding to gold revealed A $\beta$ (white arrow) and the detachment zone (black arrow). Amyloid tangles seem to be granulated once crossing the myelin sheath (black arrowheads). (d) Myelin sheath as observed in PBS-injected rat brain (magnification at $2156 \mathrm{x}$ ).

2.4. The Incorporation of Intracerebrally Injected $A \beta$ into Mitochondria Is Related to Mitochondrial Free Radical Overproduction. Brain sections were obtained from each group to determine mitochondrial mass density by using Mitotracker Green FM, a selective fluorescent dye whose mitochondria localization is independent of the membrane potential. Mitochondria from PBS-injected brains showed uniform box-like shapes regularly distributed and ranging in size from 318 to $1832 \mathrm{~nm}$ (mean $964 \pm 365 \mathrm{~nm}$ ) with an average integrated optical density (IOD) of $41.7 \pm 3.5$ (Figures 4(a) and $4(\mathrm{~b}))$. In $\mathrm{A} \beta$-injected brains, mitochondria was found to form perinuclear clusters with a size ranging from 529 to $7400 \mathrm{~nm}$ (mean $2812 \pm 1742 \mathrm{~nm}, \mathrm{IOD}=54.5 \pm 4.6$ ) (Figures $4(\mathrm{c})$ and $4(\mathrm{~d}))$. Similar clusters were observed in $\mathrm{H}_{2} \mathrm{O}_{2}$ injected rats $(P<0.05)$, and they reached a size up to $23 \mu \mathrm{m}$ (Figures 4(e) and 4(f)).
In order to correlate the presence of $\mathrm{A} \beta$ within mitochondria and overproduction of free radicals by mitochondria, 36 hours following the application of $\mathrm{fA} \beta_{1-42}$ and 2 hours before obtaining the tissue sample, CM-H2XRos, a chloromethyl derivative of dihydro-X-rosamine, was intraperitoneally injected; CM-H2XRos is a potential-dependent probe which evaluates the direct production of mitochondrial reactive oxygen species (ROS) in cells. Red CM-H2XRos dye has the ability of diffusing into living cells, labeling only actively respiring mitochondria [39] and it is well retained after fixation. Once located within cells, the reduced CM-H2XRos is oxidized by ROS to a fluorescent mitochondrion-sensitive probe and sequestered in this organelle; thus, its oxidation is useful to detect both ROS (predominantly superoxide anion, $\mathrm{O}_{2}{ }^{\bullet-}$ ) and possibly reactive nitrogen species (nitric oxide, $\cdot \mathrm{NO}$, and peroxynitrite, $\mathrm{ONOO}^{-}$). By comparing the IOD 


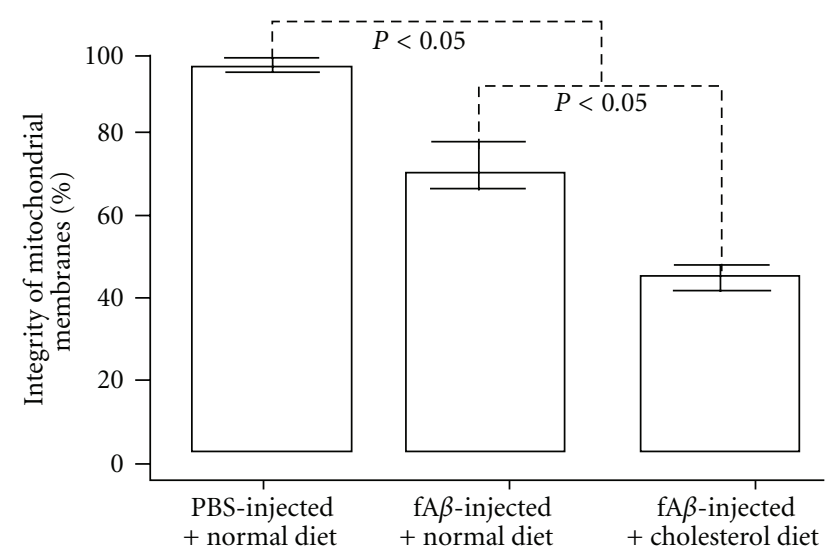

FIgURE 2: A cholesterol-enriched diet was significantly related to a more important loss of the mitochondrial integrity in animals. The graph shows differences among PBS-injected brains from animals receiving a regular laboratory rodent diet and two other groups of amyloid-injected brains. These latter were from animals receiving a normal diet and from animals receiving a cholesterol-enriched diet. Amyloid-injected brains showed significant loss of mitochondrial membrane integrity as compared to PBS-injected brains. However, those animals additionally fed with a cholesterol-enriched diet were significantly more affected.

of randomly selected regions of equal size within a single optical section, multiplied by the number of CM-H2XRosstained mitochondria, the overproduction of ROS for each group was estimated. Thus, fA $\beta$-injected brains showed a significant ROS overproduction, as expected (graph in Figure 4).

2.5. Melatonin Significantly Reduces ROS Overproduction. Orally administered $(20 \mathrm{mg} / \mathrm{kg} /$ day added to the drinking water), melatonin reached $145 \pm 8 \mathrm{pg} / \mathrm{mL}$ in serum between 01:00 and 02:00 h, which was $84 \%$ higher than controls (data not shown). At this dose, melatonin reduced significantly mitochondrial ROS overproduction, as graphically represented in Figure 5. Thus, IOD levels by mitochondrial CM$\mathrm{H} 2 \mathrm{XRos}$ in $\mathrm{fA} \beta_{1-42}$-injected brains diminished 35\% in rats taking melatonin in the drinking water, whereas in $\mathrm{H}_{2} \mathrm{O}_{2}$ intracerebrally injected rats, melatonin treatment reduced an average of ROS levels by $69 \%$ as compared with $\mathrm{H}_{2} \mathrm{O}_{2}$ intracerebrally injected rats without melatonin treatment (Figure 5).

Finally, by obtaining the quotient between ROS, estimated by CM-H2XRos, and mitochondrial mass, estimated by Mitotracker green caption, the apparently greater ability of $\mathrm{fA} \beta_{1-42}$ to cause oxidative damage with respect to $\mathrm{H}_{2} \mathrm{O}_{2}$ (graph in Figure 4), was reduced to its basal value (Figure 5). The ability of melatonin to reduce free radicals was significant in both experimental groups.

2.6. Amyloid-Beta Depresses Both the Respiratory Control Ratio and the ATPase Activity. 36 hours following the intracerebral injection of $\mathrm{fA} \beta_{1-42}$, we found $\mathrm{A} \beta$ positive immunoreactivity in mitochondria, which was closely associated to mitochondrial damage and ROS overproduction, as described above. Mitochondria were then isolated in order to examine a possible correlation between the mentioned findings with functional indicators, such as the mitochondrial respiratory control ratio (RCR) and the hydrolysis activity of F1Fo-ATPase. The former measures mitochondria ability to idle at a low rate yet respond to ADP by making ATP at a high rate [40] in such a manner that is feasible to infer the leaking of electron transfer without concomitant phosphorylation, or how much ATP-synthase is partially uncoupled from respiration; the latter, as a measure of the capacity to maintain an inner-membrane potential by coupling the energy of the electrochemical proton gradient with ATP synthesis [41]. A significant difference was obtained comparing PBSinjected $(3.8 \pm 0.03)$ and $\mathrm{fA} \beta$ groups $(2.6 \pm 0.05)(P<$ $0.05)$. This difference was significantly reduced when $\mathrm{fA} \beta$ injected animals ingested melatonin in the drinking water $(\mathrm{fA} \beta \neq \mathrm{fA} \beta+\mathrm{Mel}, P<0.05)$ (Figure 6$)$.

$\mathrm{H}_{2} \mathrm{O}_{2}$-injected brains, used as positive controls, showed a more significant reduction in $\operatorname{RCR}(2.18 \pm 0.06)$, and also responded to melatonin treatment (Figures 8 and 9 ).

Interestingly, both $\mathrm{fA} \beta$ and $\mathrm{H}_{2} \mathrm{O}_{2}$ reduced ATPase hydrolytic activity but, contrary to the RCR response, melatonin did not ameliorate this parameter $(\mathrm{fA} \beta=\mathrm{fA} \beta+\mathrm{Mel})$ (Figure 7).

In general, the more extensive oxidative damage was related to the lower the respiratory control ratio and the lower the ATPase hydrolytic activity (Figure 8).

\subsection{There Is a Direct Correlation between Oxidative Stress- Induced Low Membrane Fluidity and a Low RCR. After estab- lishing a link between the presence of $\mathrm{A} \beta$ in mitochondrion and functional disturbances in this organelle, we searched for changes in membrane fluidity. This parameter correlates with the degree of altered membrane lipid composition and it is a well-known pathogenic factor directly affecting the energetic coupling of $\mathrm{Ca}^{2+}$ pumping, with the consequent energetic failure. We found indeed, that following the intracerebral injection of $\mathrm{fA} \beta$ and its appearance inside mitochondria, a significant reduction in membrane fluidity was evident as compared to control Ie/Im fluorescence values $(\mathrm{fA} \beta 2.6 \pm 0.05$ versus $\mathrm{PBS}$-injected controls $3.5 \pm$ $0.03, P<0.001)$. Brains of animals receiving melatonin treatment showed a significant recovery (fA $\beta 2.6 \pm 0.05$ versus fA $\beta+\operatorname{Mel} 2.95 \pm 0.05, P<0.001$ ) (Figure 9).}

\section{Discussion}

Considerable experimental data favor the hypothesis that amyloid deposition in the brain is one of the etiological factors contributing to $\mathrm{AD}$ dementia [43] and the hypothesis of the "intracellular cascade of $\mathrm{A} \beta$ " has gained preponderance [18]. It has been demonstrated that $\mathrm{A} \beta_{1-42}$ uncouples the mitochondrial respiratory chain and this plays a key role in Alzheimer's pathology [44]. Structurally, $\mathrm{A} \beta$ induces swelling of isolated mitochondria $[45,46]$ and functionally decreases ATP synthesis and the activity of various mitochondrial enzymes, as demonstrated in vivo [47] and in vitro in cultured neuronal cells or in astrocytes 


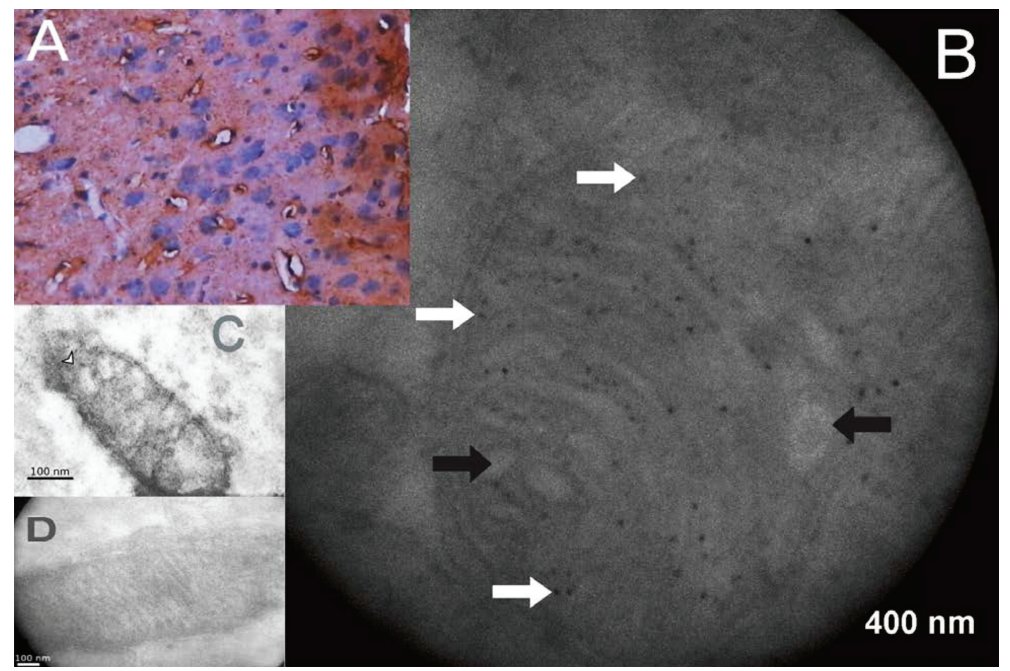

FIGURE 3: $A \beta$ in mitochondria, particularly on cristae of the inner membrane accompanied by severe disruption of the organelle. (a) Deposits of A $\beta$ aggregates into the hippocampal adjacent cortex 36 hours after injection, as shown by DAB-revealed horseradish peroxidase immunohistochemistry (40x). Congophilic amyloid deposits remained visible up to 21 days following the intracerebral injection (data not shown). (b) A $\beta$ immunoreactivity (white arrows) within mitochondria 36 hours following the injection of fA $\beta_{1-42}$ into hippocampus CA1 pyramidal neurons at 35000x magnification. The same anti-A $\beta$ polyclonal antibody used in the regular immunohistochemistry was used in this procedure but revealed with a $6 \mathrm{~nm}$ gold-labeled second antibody. Swollen mitochondria with broken cristae and its remnants intermixed with fine electron-dense dusty granule is observed. Additionally, the membrane integrity is lost and some vacuoles became evident (black arrows). (c) Highly swollen mitochondria without cristae, like enlarged sacs, containing fine electrodense granules, rupture of external mitochondrial membranes (white arrow head), and vacuolization. In this case the anti-A $\beta$ antibody was revealed with an irrelevant secondary antibody, used as control. (d) Intact mitochondrial ultrastructure of a PBS-injected control rat (37000x).

exposed to the peptide $[45,47,48]$. Thus, $\mathrm{A} \beta$-induced mitochondrial damage may be an extension of the amyloid cascade hypothesis, which 20 years ago suggested that the altered metabolism of APP was the initiating event in AD pathogenesis, subsequently leading to the aggregation of $\mathrm{A} \beta$, specifically $\mathrm{A} \beta_{1-42}[43,49]$. Later, different neurotoxic mechanisms for $\mathrm{A} \beta$ were proposed, including disruption of mitochondrial function via binding of the $A \beta$-binding alcohol dehydrogenase (ABAD) protein [19], or formation of ion channels allowing calcium uptake which induces neuritic abnormalities in a dose- and time-dependent fashion [50], or the opening of the mitochondrial permeability transition pore coupled to inhibition of respiratory complexes $[51,52]$.

A common underlying factor is the overactivation of microglia with the consequent overexpression of proinflammatory cytokines and a significant increase in ROS, which always prevails [53-56]. ROS, in turn, may come from an innate immune response promoted by damaging signals $[55,57]$ or they may come from the damaged mitochondria [58]. This latter implies a pathological vicious cycle, where mitochondrial dysfunction and ROS leakage from the respiratory chain feed each other. However, there is a pertinent question, is the mitochondrial impairment a consequence of intraneuronal deposits of endogenous oligomeric species of $\mathrm{A} \beta$ ? Or are the extracellular deposits of $\mathrm{fA} \beta$ capable of reaching mitochondria, causing their deterioration before the appearance of plaques?

APP has been localized to the trans-Golgi network, endoplasmic reticulum (ER), and endosomal, lysosomal, and mitochondrial membranes. Thus, the liberation of $A \beta$ and formation of intracellular accumulations could potentially occur wherever APP and the $\beta$ - and $\gamma$-secretases are localized, which is particularly true when APP is overexpressed (reviewed in [59]); this was not the case for the animals used in the current experimentation. The data presented here, obtained from aged Wistar rat brains, demonstrate that mitochondria undergo major structural and physiological changes following the intracerebral injection of $\mathrm{fA} \beta_{1-42}$, which in turn led to the formation of extracellular deposits which eventually appeared in mitochondria.

Mitochondrial genes seem to be activated before plaque formation, in addition to an increase in $\mathrm{H}_{2} \mathrm{O}_{2}$ content, accompanied by a decrease in cytochrome oxidase activity, as demonstrated in young Tg2576 mice prior to the appearance of $A \beta$ plaques [20]. It is not clear whether a soluble, intramitochondrially produced $\mathrm{A} \beta$ could cause impairment of the electron transport chain since, according to the theoretical disposition of APP within the mitochondrial membrane [60], $A \beta$ would have to be imported from outside the mitochondria, from the cytosol. This phenomenon has been revealed and involves the translocase of the outer membrane (TOM) and the translocase of the inner membrane (TIM), as shown in human cortical brain tissue specimens by Hansson Petersen et al. [21].

However, $\mathrm{A} \beta$ has the ability by itself to permeabilize membranes. Without discarding that $\mathrm{A} \beta$ from the cytosol may invade mitochondria, it is worth to consider the huge amounts of extracellular $\mathrm{A} \beta$, forming plaques outside the neurons, even visible to conventional light microscopy. $\mathrm{A} \beta$ peptides are amphipathic molecules, 


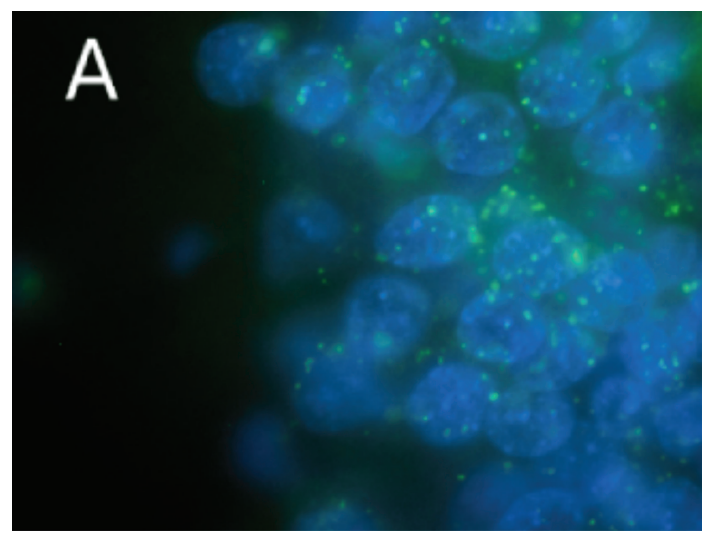

(a)

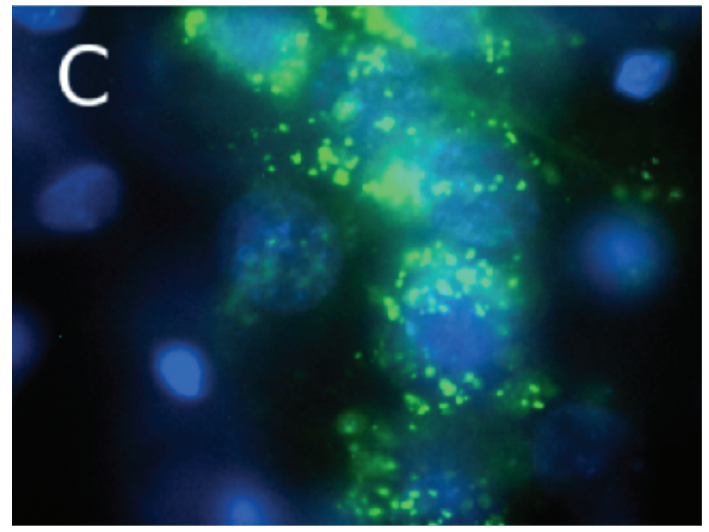

(c)

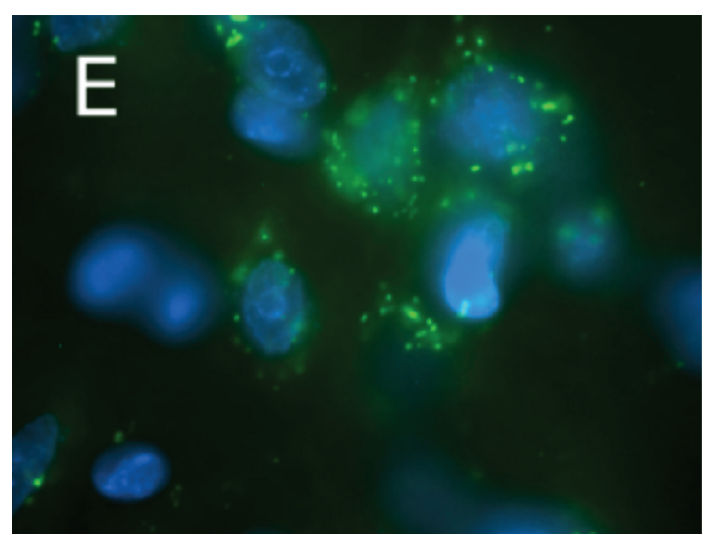

(e)

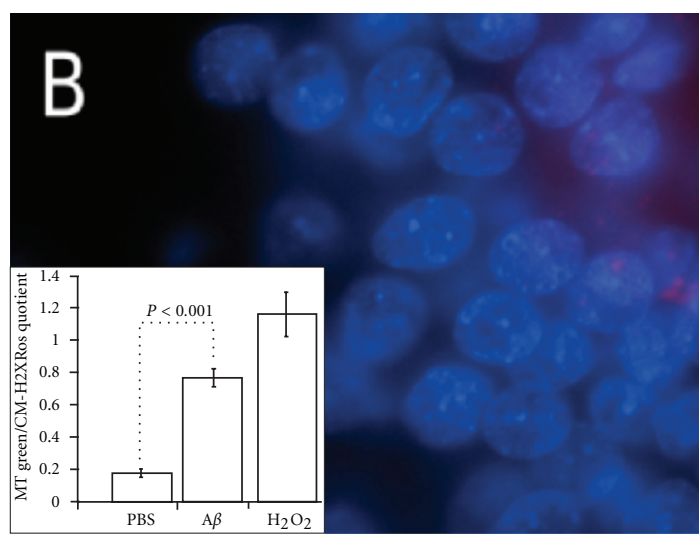

(b)

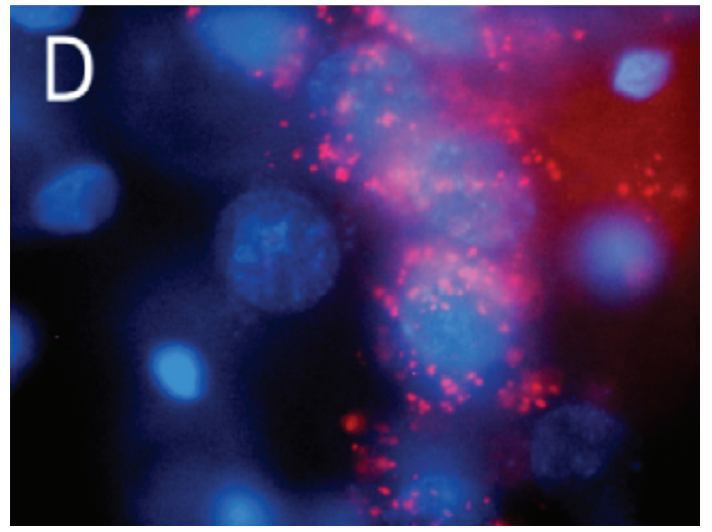

(d)

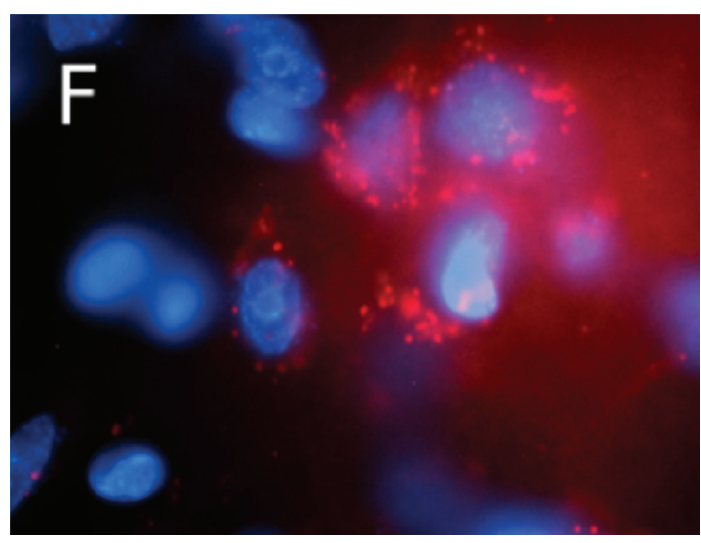

(f)

FIGURE 4: The presence of $\mathrm{A} \beta$ within mitochondria is related to ROS overproduction. Control brain exhibited a regular distribution of mitochondria (a) with a size of $964 \pm 365 \mathrm{~nm}$, according to Mitotracker Green staining, which is essentially nonfluorescent in aqueous solutions but becomes fluorescent as it accumulates in the mitochondrial membranes. Nuclei appear in blue, stained with DAPI. The amount of mitochondrial ROS in control PBS-injected brain was negligible, as inferred from CM-H2XRos staining, which specifically accumulates inside mitochondria because of the positive charge it acquires upon oxidation by intracellular ROS (b). CM-H2XRos was intraperitoneally injected in vivo 2 hours before obtaining the tissue sample. fA $\beta$-injected brains showed a different distribution of mitochondria, predominantly perinuclear, ranging in size from 529 to $7400 \mathrm{~nm}$ and forming clusters (c), (d). Integrated optical density (IOD) of CM-H2XRos-stained mitochondria was significantly $(P<0.001)$ elevated in $\mathrm{fA} \beta$ - and $\mathrm{H}_{2} \mathrm{O}_{2}$-injected brains (e), as compared with controls (d), (f). In order to estimate how many mitochondria from the mitochondrial mass were overproducing ROS, we divide the IOD of MT-Green by IOD of CM-H2XRos for each group, and we found a significant difference between fA $\beta$-injected brains and controls as shown in the attached graphic $(P<0.001)$. 

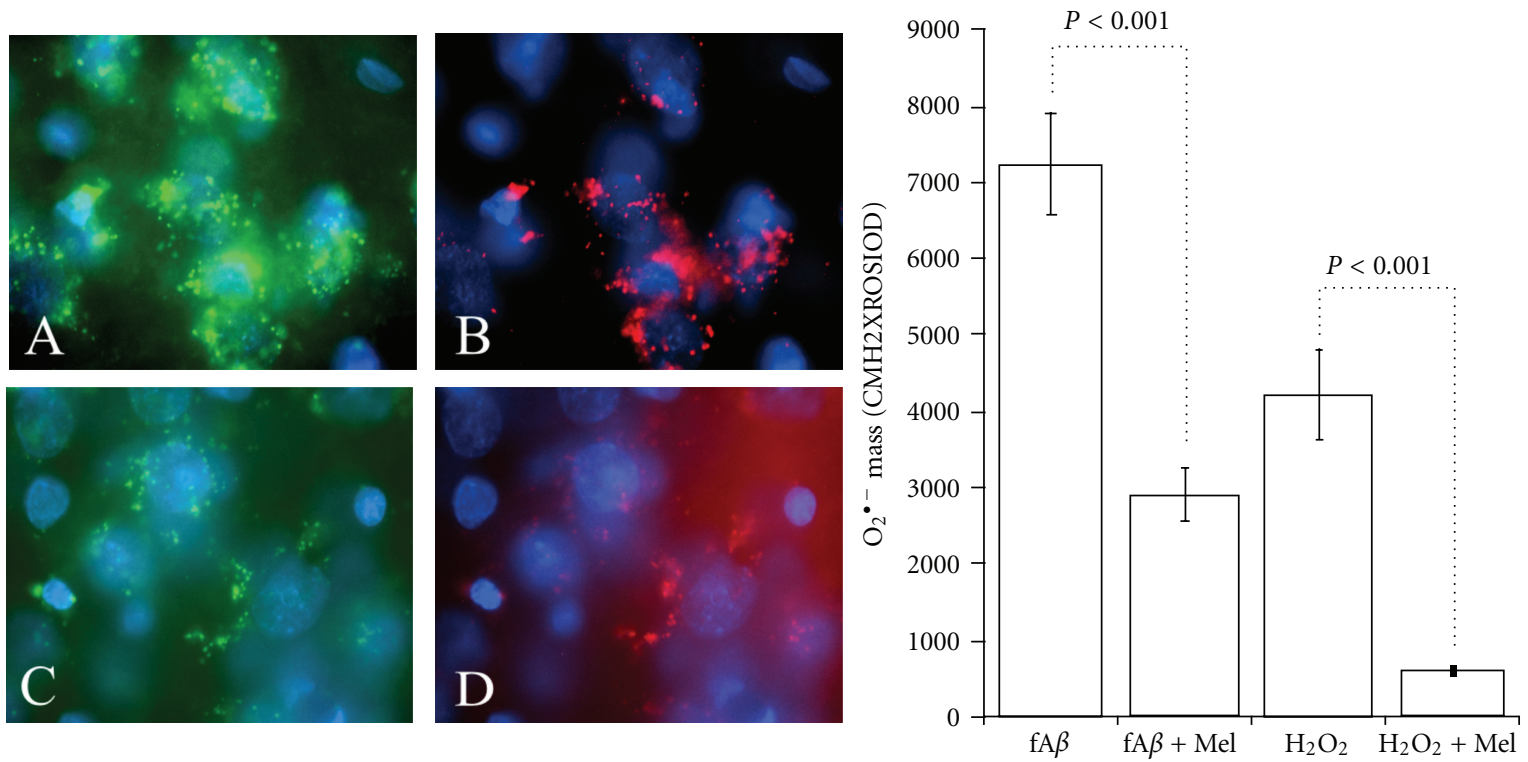

FIGURE 5: Melatonin reduces significantly mitochondrial ROS overproduction. As expected, melatonin reduced the fluorescence derived from CM-H2XRos oxidation in both the fA $\beta$ - and the $\mathrm{H}_{2} \mathrm{O}_{2}$-injected brains. According to Figure 4 most of the mitochondria in brains injected with $\mathrm{A} \beta$ or $\mathrm{H}_{2} \mathrm{O}_{2}$ were producing free radicals. Now, by comparing the intensity of free radicals produced in brain of animals receiving melatonin treatment against those animals without melatonin, a very significant decrease in the amount of produced free radicals was observed, as shown in the graph.

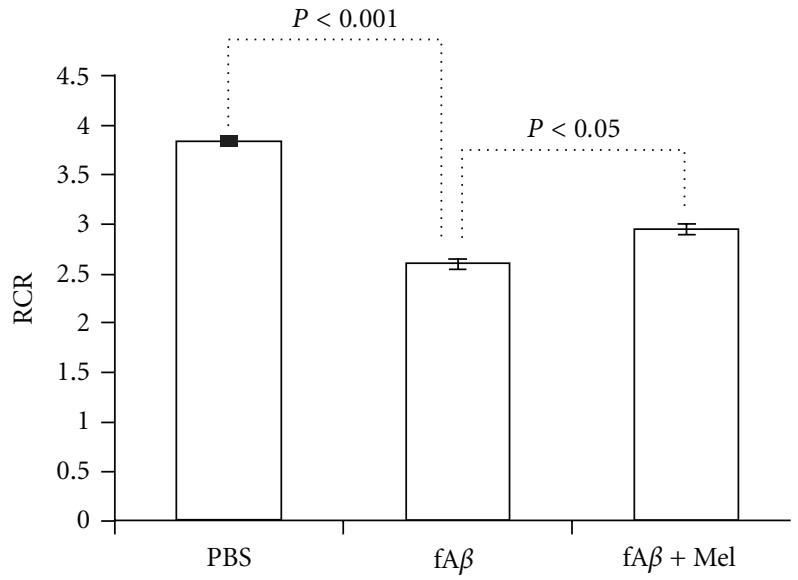

FIgURE 6: $\mathrm{A} \beta$-induced mitochondrial dysfunction. In order to correlate both the presence of $\mathrm{A} \beta$ within mitochondria and the overproduction of ROS with functional alterations in mitochondria, oxygen consumption in isolated mitochondria $(1 \mathrm{mg} / \mathrm{mL})$ was measured using a Clark-type oxygen electrode at $34^{\circ} \mathrm{C}$ in treatment buffer, adding succinate as substrate. The respiratory control ratio [state 3 rate] : [state 4 rate], as an indicator of the appropriate coupling between respiration and phosphorylation, revealed a significant decrease in $\mathrm{fA} \beta$ - and $\mathrm{H}_{2} \mathrm{O}_{2}$-injected brains, as compared to controls $(P<0.001)$. However, a significant improvement in the RCR was observed in animals treated with melatonin $(P<0.05)$.

containing a hydrophilic N-terminal stretch (residues 128) and a hydrophobic C-terminal domain (residues 2940/42) partially spanning the APP transmembrane domain. In solution, $\mathrm{A} \beta$ peptides display a substantially unfolded conformation with reduced content of secondary structure; however, the latter increases considerably in phospholipid vesicles particularly when enriched in cholesterol and gangliosides $[61,62]$. The ability of $\mathrm{A} \beta$ to insert into membranes depends more on the cholesterol: phospholipid ratio. By using the same experimental design as in this report, we have found important evidence on $\mathrm{A} \beta$-induced alterations in the lipid content of mitochondrial membranes, in part related possibly to a direct $\mathrm{A} \beta$ molecular interaction and in part related to $\mathrm{A} \beta$-induced oxidative stress (unpublished data). Oxidative stress, on the other hand, may induce membrane permeabilization by itself, as revealed by neutron reflectometry in lipid bilayers [63], whereas aging is related to changes in the cholesterol, sphingomyelin, and phospholipid content in membranes $[61,64,65]$. Thus, according to our hypothesis, all these factors are concentrated to facilitate $\mathrm{A} \beta$ entry into the cell and eventually to the mitochondria.

In fact, a preferential adsorption, internalization, and resistance to degradation of the major isoform of the $A \beta$ peptide, $\mathrm{A} \beta_{1-42}$, has been shown in differentiated PC12 cells. The amount of peptide internalized increases proportionally with the concentration of peptide in the medium and the amount of internalized $\mathrm{A} \beta_{1-42}$ is approximately 5 -fold higher than the amount of $A \beta_{1-40}[66]$.

$\mathrm{A} \beta$, extracellularly applied to human neuroblastoma SH-SY5Y cells, was demonstrated to be internalized and taken up by mitochondria [21]. In other experiments in vivo, fluorescence in isothiocyanate- (FITC-) labeled $\mathrm{A} \beta_{1-42}$ introduced via tail vein injection into mice with a blood brain barrier $(\mathrm{BBB})$ rendered permeable by treatment with pertussis toxin, readily crossed the permeabilized $\mathrm{BBB}$ and 48 hours later $\mathrm{A} \beta_{1-42}$-positive neurons were widespread 


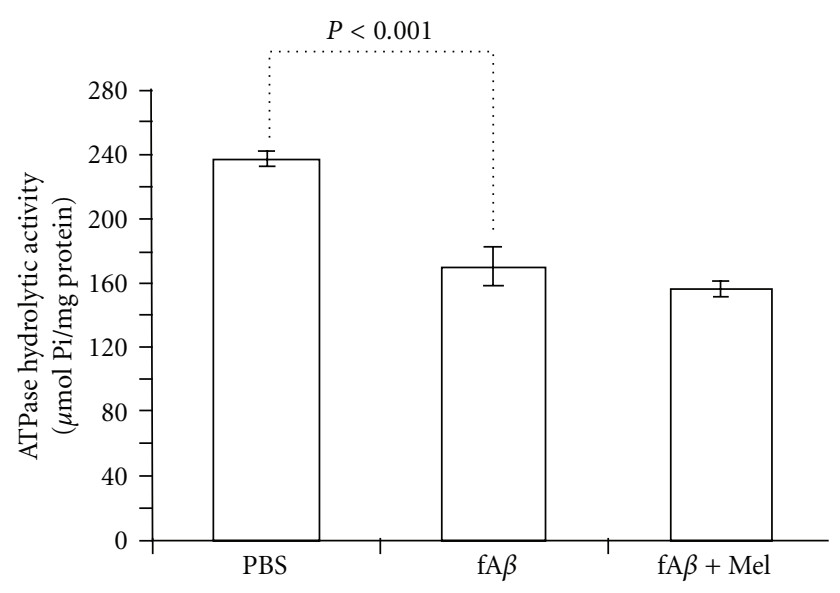

Figure 7: The hydrolytic activity of ATPase did not respond to melatonin. Enzymatic ATP hydrolysis was determined by a colorimetric reaction measuring the release of free orthophosphate (Pi), based on the formation of a phosphomolybdate complex in an acid medium followed by a reduction or complexation with basic dyes that yield colored complexes. When electron transport ceases, the inner-membrane potential is developed at the expense of ATP hydrolysis by the mitochondrial ATP synthase. However, in the presence of $\mathrm{A} \beta$ the hydrolytic activity of ATPase decreases significantly as compared to intact brains $(P<0.001)$ and did not show any recovery in melatonin-treated animals $(\mathrm{fA} \beta=\mathrm{fA} \beta+\mathrm{Mel})$, which may imply a different mechanism of damage by $\mathrm{A} \beta$. In fact, another report explores the possibility of a direct interaction of $\mathrm{A} \beta$ with the alpha subunit of the F1Fo-ATP synthase complex [42].

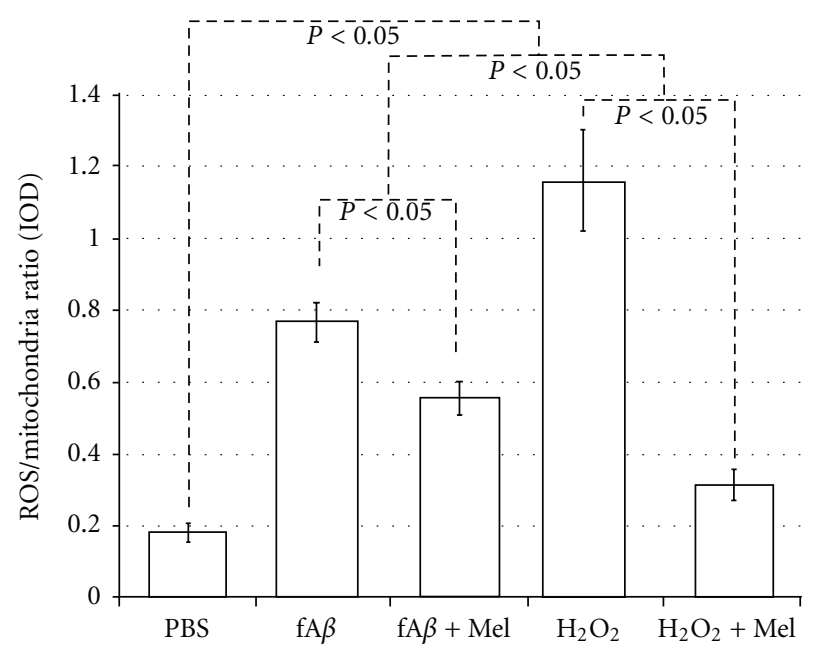

FIGURE 8: ROS/mitochondria ratio. The amount of mitochondria producing free radicals (ROS/mitochondria ratio) is larger in $\mathrm{fA} \beta$ and $\mathrm{H}_{2} \mathrm{O}_{2}$-injected brains without melatonin treatment, but the effect is significantly reduced by using melatonin.

[67]. These experiments demonstrate the possibility that extracellular $A \beta$, even exogenous $A \beta_{1-42}$, may be the source of the intraneuronal $A \beta$. Once inside the neurons, $A \beta$ is responsible for mitochondrial damages, as we demonstrated. We have shown in healthy rat brain that following the intracerebral injection of $\mathrm{fA} \beta_{1-42}$, this peptide accumulates in plaques outside of the cells. There was not another preexisting pathological condition or predisposition, and experiments have been carried out under in vivo conditions. The extracellular accumulation of $\mathrm{fA} \beta_{1-42}$ coincided with axonal degeneration and positive $A \beta$ immunoreactivity within mitochondria, accompanied by ultrastructural alterations consistent with mitochondrial dysfunction. All of this also coincide with Saavedra et al. [2] who found that extracellular $A \beta$ contributes to the intracellular pool of $A \beta$ and its internalization is not dependent of ApoE, but it is a lipid raft-mediated mechanism. Additionally, $A \beta$ was shown to be more efficiently internalized by axons than by cell bodies.

We found, as mentioned before, axonal degenerative changes with elevated $\mathrm{A} \beta$ immunoreactivity (Figure 1). It is possible that this axonal degeneration could be the origin of demyelination and a pathway to permit the entry of $A \beta$ into the neurons via retrograde transport. Previous reports have revealed increased quantities of $\mathrm{A} \beta$ and $\mathrm{A} \beta_{1-42}$ in $\mathrm{AD}$ white matter accompanied by significant decreases in the amounts of myelin basic protein, myelin proteolipid protein, and $2^{\prime}, 3^{\prime}$-cyclic nucleotide $3^{\prime}$-phosphodiesterase. These observations suggest that extensive white matter axonal demyelination underlies Alzheimer's pathology, resulting in loss of capacitance and serious disturbances in nerve conduction, severely damaging brain function [68]. A new hypothesis suggests that myelin breakdown in the late-myelinating brain regions releases iron, which promotes the development of the toxic amyloid oligomers and plaques, which in turn destroy more myelin $[69,70]$ (Figure 1). It is worth mentioning that iron is strongly related to oxidative stress and oxidative stress is a key protagonist in neurodegenerative diseases $[8,10,15$, $24,71,72]$. Additionally, we have also found a significant $\mathrm{A} \beta$-induced rearrangement in membrane cholesterol and fatty acid composition both in cytoplasmic membranes and in mitochondrial membranes (data not shown), which culminate with a significant alteration in membrane fluidity (Figure 9).

It is well known that high levels of circulating cholesterol does not mean high cholesterol concentrations in brain tissue, essentially because cholesterol in the blood does not cross the blood brain barrier (BBB). However, hypercholesterolemia has certain association with accumulation of $A \beta$ peptide in brain. The mechanism is not well understood, but the oxidized cholesterol metabolite 27-hydroxycholesterol likely plays a key role. Our results (Figures 2 and 9) coincide with the results from other reports [73-75].

Once the internalization of $A \beta$ and its ability to infiltrate mitochondria were documented, we proceeded to evaluate the overproduction of mitochondrial free radicals induced by the presence of $\mathrm{A} \beta$, by using CM-H2XRos, a rosamine derivative well retained after fixation, which was intraperitoneally injected in vivo. This approach allowed us to examine the free radicals overproduction without changing the natural architecture of brain tissue or the interrelationship between cells. Changes in the mitochondrial mass and $A \beta$ linked conformational alterations were explored by using Mitotracker green, applied ex vivo on tissue brain slices. 


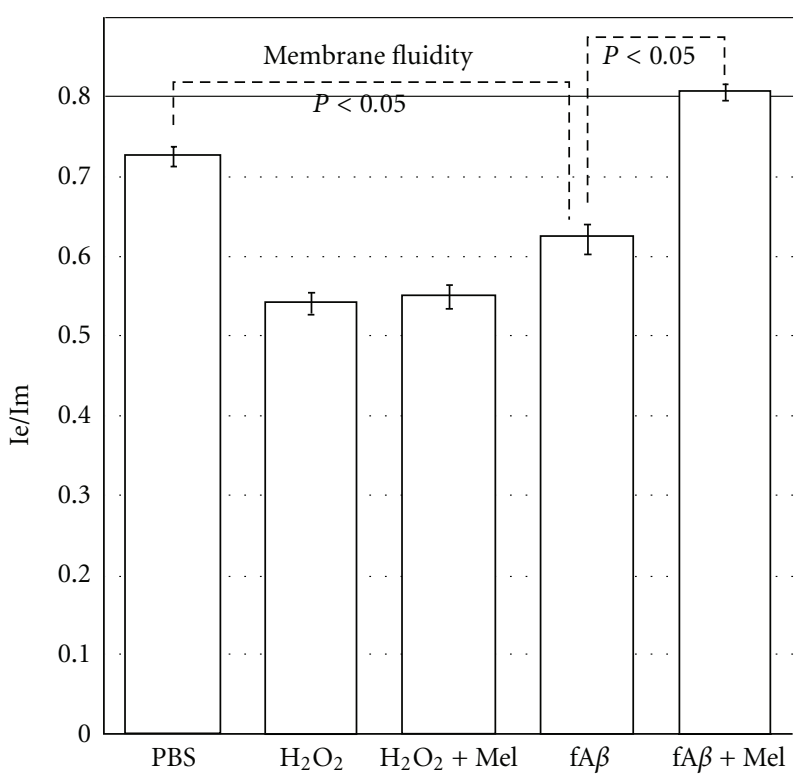

(a)

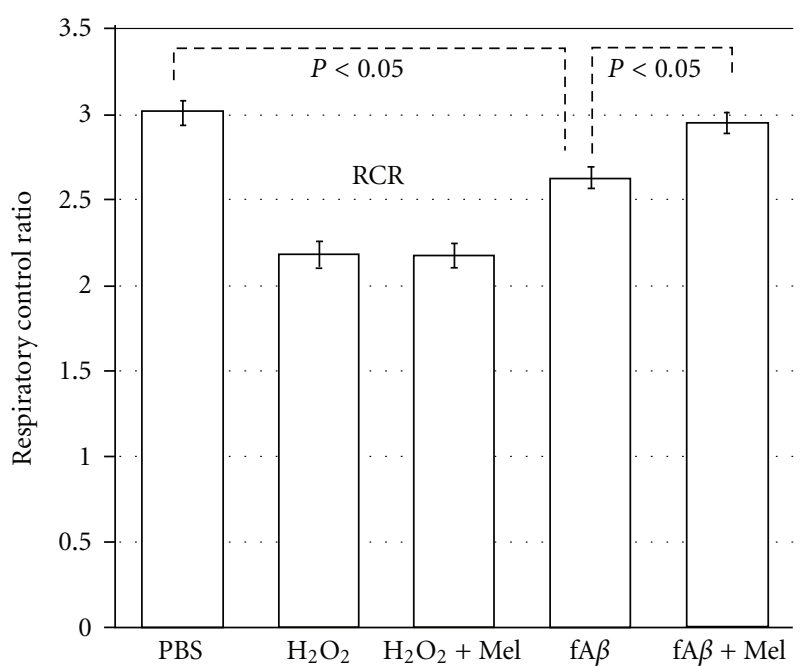

(b)

FIGURE 9: A $\beta$ reduces mitochondrial membrane fluidity closely related to free radical overproduction and to the respiratory control ratio. Measured by estimating the excimer to monomer fluorescence intensity ratio (Ie/Im) of DPP, membrane fluidity in mitochondrial membranes was evaluated in order to show how $\mathrm{A} \beta$, imported from the outside the cell membrane, is able to cause mitochondrial damage once incorporated within this organelle. We found that the groups producing more free radicals (fA $\beta$ and $\mathrm{H}_{2} \mathrm{O}_{2}$ groups), showed more altered membrane fluidity and RCR as compared to PBS-injected brains used as controls $(P<0.001)$. By using melatonin, both membrane fluidity and RCR were significantly ameliorated (fA $\beta+$ Mel and $\mathrm{H}_{2} \mathrm{O}_{2}+$ Mel groups).

Oxidative stress and $\mathrm{A} \beta$ toxicity are interdependent phenomena. In fact, the pathological effects of $A \beta$ heavily depend on its capacity to provoke oxidative stress [42]. There are two major means by which $\mathrm{A} \beta$ induces oxidative stress, one is through the activation of the NADPH-oxidase probably both in neurons and in glia [76, 77], which links redox control and neuroinflammatory signaling pathways [68]. The other means by which $A \beta$ induces oxidative stress is related to mitochondrial damage, a mechanism closely linked to apoptosis [78]. Reciprocally, oxidative stress induces intracellular accumulation of $\mathrm{A} \beta$ through enhancing the amyloidogenic pathway [79]. $\mathrm{H}_{2} \mathrm{O}_{2}$ is a wellknown uncoupler of the mitochondrial respiratory activity, producing a concentration-dependent inhibition of state 3 (ADP-stimulated) respiration and reducing substantially the ADP : O ratio [80]. An evaluation of electron transport chain complexes and Krebs cycle enzymes revealed that alpha-ketoglutarate dehydrogenase, succinate dehydrogenase, and aconitase are susceptible to inactivation, which is a reversible process [81]. Melatonin directly detoxifies $\mathrm{H}_{2} \mathrm{O}_{2}$ with the resulting product being N1-acetyl-N2-formyl-5methoxykynuramine which is also an efficient free radical scavenger $[81,82]$. For this reason $\mathrm{H}_{2} \mathrm{O}_{2}$ was selected as positive control and the RCR as well as the hydrolytic activity of ATPase in $\mathrm{H}_{2} \mathrm{O}_{2}$-injected brains responded favorably to melatonin treatment, which implies that oxidative stress may explain those alterations. However, in fA $\beta$-injected brains, melatonin had a favorable influence on the RCR, but it failed to modulate the ATPase hydrolytic activity. This finding explains the energy hypometabolism linked to $A \beta$, since
ATPase hydrolytic activity is responsible for generating a proton gradient at the expense of ATP. Interestingly, $A \beta$ is similar in structure to the ATP synthase-binding sequence of the inhibitor of F1 (IF1), a naturally occurring inhibitor of the ATPase activity of the F1Fo-ATP synthase complex in mitochondria. Thus, as with IF1, A $\beta$ may inhibit ATPase activity presumably by interacting with the alpha subunit of the F1Fo-ATP synthase complex [83]. We speculate that this direct interaction could cause the failure of the antioxidant therapy to restore the ATPase hydrolytic activity in $\mathrm{fA} \beta$-injected brains. Even though melatonin has been demonstrated to improve mitochondrial function in both normal and pathological conditions, this effect is related to its antioxidant activity.

Melatonin did not seem to have a direct effect on the ATPase hydrolytic activity. However, this endogenous neurohormone incorporates into mitochondria and may decrease oxygen consumption concomitantly with its concentration, inhibiting any increase in oxygen flux in the presence of an excess of ADP, and reducing the membrane potential, changes that inhibit the production of $\mathrm{O}_{2}{ }^{--}$and $\mathrm{H}_{2} \mathrm{O}_{2}$, as demonstrated in mouse liver cells [84]. Moreover, by using melatonin it is possible to maintain the efficiency of oxidative phosphorylation and ATP synthesis, while increasing the activity of the respiratory complexes (mainly complexes I, III, and IV) [84]. Melatonin also has proven to be effective in preventing mitochondrial nitric oxide synthase induction in parkinsonian mice [85]. However, melatonin also failed to restore the nitrosative stress-induced failure in the ATPase hydrolytic activity in septic mice [86]. These data suggest that 
$\mathrm{A} \beta$-induced mitochondrial alterations, as those described at early stages in $\mathrm{AD}$ before the appearance of amyloid plaques, are the result of internalization of $A \beta$. Later, continuous overproduction of amyloid peptide, which induces more oxidative stress [44] and neuroinflammation [55, 87], results in extracellular plaque formation. Thus, the effects of $A \beta$ on mitochondria could be an extension of the amyloid cascade. The results presented here support the hypothesis of the internalization of $A \beta$ as a major cause of mitochondrial dysfunction during $\mathrm{AD}$.

Concluding Remarks. Extracellular deposits of $\mathrm{A} \beta$ may access mitochondria because of the $A \beta$ ability to permeabilize cellular membranes and lipid bilayers. Thus, $A \beta$ can pass through the membranes from outside in the extracellular space, where these deposits become so huge they form plaques, visible with conventional microscopy. The role of $\mathrm{A} \beta$-induced membrane damage and the ability of $\mathrm{A} \beta$ to pass through different compartments are fundamental to understand the mitochondrial energetic failure. All the above mentioned, in a context where lipids and associated oxidative stress play a key role.

\section{Materials and Methods}

4.1. In Vivo A $\beta$-Injected Model. Surgical and animal care procedures were performed with strict adherence to the guide for the care and use of laboratory animals (National Institutes of Health, publication number 86-23, Bethesda, MD, USA). All protocols and procedures were approved by the institution's Animal Care and Use Committee. Male Wistar rats (250-280 grams; 3-month-old) were housed in pairs in a colony room on a 12:12 dark/light cycle with lights off at 20:00 h; food and water were provided ad libitum. The rats were divided $(n=5)$ in the following groups: (1) vehicle (PBS) injected rats, (2) fibrillar $\mathrm{A} \beta_{1-42}$-injected rats (fA $\beta$ ), and (3) $\mathrm{H}_{2} \mathrm{O}_{2}(200 \mu \mathrm{M})$ intracerebrally injected rats $\left(\mathrm{H}_{2} \mathrm{O}_{2}\right)$. Two additional groups, $\mathrm{fA} \beta+\mathrm{Mel}$ and $\mathrm{H}_{2} \mathrm{O}_{2}+$ Mel were included. In this case, $\mathrm{fA} \beta$ or $\mathrm{H}_{2} \mathrm{O}_{2}$-intracerebrally injected animals received antioxidant treatment with melatonin (Sigma, St. Louis, MO, USA), which was dissolved in the watering vessel at a dose of $20 \mathrm{mg} / \mathrm{kg} /$ day [24]. $\mathrm{H}_{2} \mathrm{O}_{2}$ was used as a positive control because of its powerful oxidizing capacity and its particular ability to alter mitochondria state $3 \mathrm{NADH}$-linked respiration [88]. The utility of vehicle solutions as controls against $A \beta$, such as saline solution or PBS has been well established from published data $[89,90]$. $\mathrm{A} \beta$ exhibits a chemistry that facilitates the formation of reactive free radical peptides. It is acceptable to use PBS instead of $A \beta$ peptides because even non-toxic $A \beta$ derivatives, not excluding the scrambled $\mathrm{A} \beta$, a usual control in this in vivo model, possess alkylsulfides which may react with oxygen in a metal-independent manner to produce a sulfoxide [91]. Also, these derivatives may generate PBN adducts, indicating the presence of peptide-derived free radical species [72].

Hippocampal injections of $\mathrm{A} \beta_{1-42}$ (2 microliters at a final concentration of $1 \mathrm{mM}$ ) were performed as previously described $[10,24,71]$. Lyophilized synthetic $\mathrm{A} \beta_{1-42}$ (Sigma, St. Louis, MO, USA) peptide was solubilized $\left(10^{-4} \mathrm{M}\right)$ in filtered, sterile PBS, then was allowed to incubate with continuous agitation (Teflon stir bar at $800 \mathrm{rpm}$ ) at $23^{\circ} \mathrm{C}$ for $36 \mathrm{~h}[71,92]$ in order to form fibrillar aggregates. Rats, anaesthetized with chloral hydrate $(350 \mathrm{mg} / \mathrm{kg}$, i.p.), were placed in a stereotaxic instrument for the intracerebral injections over a $5 \mathrm{~min}$ period (coordinate: anterior-posterior $=-3.8 \mathrm{~mm}$, medial-lateral $=2.0 \mathrm{~mm}$, dorsal-ventral $=2.6 \mathrm{~mm}$ from bregma [93], using 5-microliter Hamilton microsyringe coupled with a 30 gauge needle through flexible tubing. The needle was left in place for $5 \mathrm{~min}$ after injection. The same coordinates were used for PBS-injected controls and the $\mathrm{H}_{2} \mathrm{O}_{2}$ experimental group.

36 hours after the injections, rats were deeply anesthetized and transcardially perfused with $200 \mathrm{~mL}$ of PBS. Those animals used for immunohistochemical procedures were additionally perfused with $4 \%$ paraformaldehyde. Brain was removed and a piece of tissue $(164-180 \mathrm{mg})$, including the lesioned area, was taken with a punch (diameter $10 \mathrm{~mm}$ ), at the base of the needle tract. This piece included the hippocampal tissue and adjacent cortical areas.

4.2. Immunohistochemistry. For $\mathrm{A} \beta$ immunohistochemistry, $5 \mathrm{~mm}$ brain slices were postfixed with paraformaldehyde for $2 \mathrm{hr}$, washed in PBS, and cut into $25-30 \mu \mathrm{m}$ thick sections with a Vibratome (Leica). Immunohistochemical staining was carried out using a routine immunoperoxidase technique on free-floating sections. Tissue was first washed in $0.05 \mathrm{M}$ PBS, then rinsed in $1 \% \mathrm{H}_{2} \mathrm{O}_{2}$ in PBS, washed in $0.05 \mathrm{M}$ PBS, and preincubated in PBS containing $0.3 \%$ Triton $\mathrm{X}-100$ (PBST); sections were then incubated overnight at room temperature with rabbit anti- $\mathrm{A} \beta$ antiserum (anti- $\beta \mathrm{A}_{42}$, $1: 1500$, from Santa Cruz) in $0.1 \%$ PBST. After $15 \mathrm{~h}$, tissue was washed twice in $0.3 \%$ PBST followed by incubation with a horseradish peroxidase-bound goat anti-rabbit IgG secondary antibody for 2 hours (Santa Cruz Biotechnology, Inc.). The tissue was washed in $0.3 \%$ PBST, then in PBS, and then reacted with 3,3'-diaminobenzidine (DAB) (Sigma Chemical Company).

For the immunoelectron microscopy, hippocampus tissue samples were fixed in $4 \%$ paraformaldehyde for 24 hours and immersed in sucrose in $2.3 \mathrm{M}$ for 24 hours. Small blocks were cut and postfixed in osmium tetroxide $2 \%$ in PB $0.2 \mathrm{M}$ for 45 minutes, then embedded for 48 hours in Embed 812 (Electron Microscopy Sciences). Ultrathin sections of 70$90 \mathrm{~nm}$ were cut with an ultramicrotome (Reichert Om3) and mounted on nickel grids, then incubated for 2 hours in $5 \%$ BSA and $0.1 \%$ fish gelatin. For immunolabeling experiment, the mounted sections were then incubated for 24 hours at $4{ }^{\circ} \mathrm{C}$ with the primary polyclonal antibody AntiA $\beta$ (Santa Cruz Biotechnology) at dilution 1:1000 and then washed four times with PBS $0.1 \mathrm{M}$ and $0.1 \%$ tween-20, and further incubated for 3 hours at room temperature with a $6 \mathrm{~nm}$ gold-conjugated secondary goat anti-rabbit antibody (Jackson Immunoresearch Laboratories) at dilution 1:500. After four washes with PBS, sections were counterstained with $2 \%$ uranyl acetate for 15 minutes and lead citrate for 5 minutes and examined in a Zeiss EM 906 transmission electron microscope (Oberkochen, Germany). 
4.3. Diet. In order to underline the importance of cholesterol in the neuronal $\mathrm{A} \beta$-induced damage, animals intracerebrally injected with $\mathrm{fA} \beta$ were divided in two groups, one receive regular Laboratory Rodent Diet chows, while the other group was fed with $4 \%$ cholesterol-enriched chows plus $1 \%$ colic acid (Harlan Teklan TD. 01418). Images were analyzed by using Image Pro-Plus software (v5.1) and structural damages were determined as a percentage of the damaged membranes against complete, healthy mitochondrial membranes per field.

4.4. Analysis of Mitochondrial Free Radical Generation. Mitotracker red CM-H2XRos (Molecular Probes), a rosamine derivative used to detect mitochondrial free radicals, was diluted in DMSO to form a $1 \mathrm{mM}$ stock solution. $100 \mu \mathrm{L}$ of that solution were diluted in $5 \mathrm{~mL}$ of saline physiological solution and stored sterile at $4^{\circ} \mathrm{C}$ as working solution. Applied at a dose of $0.030 \mu \mathrm{g} / \mathrm{kg}, \mathrm{CM}-\mathrm{H} 2 \mathrm{XR}$ os did not affect the functional properties of mitochondria after loading, since neither respiratory output nor cell viability was significant changed, as evaluated in a separate study (data not shown). Two hours following the intraperitoneal injection of CMH2XRos, animals were perfused transcardially with PBS followed by $4 \%$ paraformaldehyde. The brains were immediately removed and immersed in the fixative for 8-10 h. Following a brief washing in PBS, brain slices were cut into 25-30 $\mu \mathrm{m}$ thick sections, including the area of interest, with the vibratome and incubated free-floating in MitoTracker Green (Molecular Probes, Ex/Em 490/516 nm), which selectively stains mitochondria both in live cells and in cells that have been fixed [94]. Then sections were mounted on adhesive (Vecta Bond)-coated glass slides, with a DNA dye, 4',6-diamidino-2-phenylindole (DAPI), containing mounting medium (Vectashield, Vector Laboratories) in order to evaluate mitochondrial mass in cells with nuclear counterstaining in blue (Ex/Em 359/461 nm). The mitochondrial free radicals were analyzed by monitoring the oxidized fluorescence product (Ex/Em 554/576 nm) of CMH2XRos under a fluorescence microscope (Carl Zeiss Axioskop). Integrated optical density (IOD), number of mitochondria, as well as its mitochondrial area was determined by using image analysis software (Image-Pro Plus v5.1).

4.5. Mitochondrial Isolation. Briefly, brain tissue was minced and placed in prechilled Dounce homogenizer with SHE buffer $(0.25 \mathrm{M}$ sucrose, $5 \mathrm{mM}$ HEPES and $1 \mathrm{mM}$ EGTA, PH 7.4 ), followed by centrifugation at $2500 \mathrm{rpm}$ for $10 \mathrm{~min}$, $4^{\circ} \mathrm{C}$, recentrifugation of the supernatant $(8500 \mathrm{rpm}, 10 \mathrm{~min})$ obtain a crude mitochondrial pellet, which in turn, following a 10 min incubation in ice, was resuspended again in SHE plus delipidized bovine serum albumin (Sigma Chemical Company). Albumin was eliminated by centrifugation of the mitochondrial suspension at $9500 \mathrm{rpm}, 10 \mathrm{~min}$. The protein content in the mitochondrial fraction was determined using the Lowry method [95].

4.6. Respiratory Control Ratios (RCRs). The measurement of oxygen consumption ratios was performed at $34^{\circ} \mathrm{C}$ using an incubation chamber with a water jacket and a Clark-type $\mathrm{O}_{2}$ electrode (Yellow Spring Instrument Co., Yellow Spring, $\mathrm{OH}$, USA) and the respiratory control ratios calculated according to Chance and Williams [96]. $1.9 \mathrm{~mL}$ of airsaturated KME buffer (125 mM KCl, $20 \mathrm{mM}$ MOPS, $5 \mathrm{mM}$ $\mathrm{MgCl}$ and $0.1 \mathrm{mM}$ EGTA at $\mathrm{pH} \mathrm{7.6)}$ was added to the chamber and equilibrated with the oxygen electrode for $3 \mathrm{~min}$ with stirring. Freshly prepared mitochondria (1 mg protein $/ \mathrm{mL}$ ) were then added to the buffer in the chamber and incubated for another $3 \mathrm{~min}$ with stirring. Respiration was started by adding $5 \mathrm{mM}$ orthophosphate (Pi), $5 \mathrm{mM}$ succinate and $1 \mathrm{mM}$ ADP. For oxidation of succinate, small amounts of ADP stimulated respiratory ratios (State 3 ) until ADP became exhausted (State 4 ). The respiratory control ratio (RCR) was calculated from the ratio of state $3 /$ state 4 oxygen consumption ratios.

4.7. ATPase Hydrolytic Activity. ATPase activity was measured at $40^{\circ} \mathrm{C}$ in a medium $(1 \mathrm{~mL})$ containing $125 \mathrm{~mm}$ $\mathrm{KCl}, 40 \mathrm{mM}$ MOPS ( $\mathrm{pH}=8$ ), $3 \mathrm{mM} \mathrm{MgCl}_{2}$, plus $0.1 \mathrm{mg}$ of mitochondrial protein, and the reaction was initiated with $40 \mu \mathrm{L}$ of ATP $(75 \mathrm{mM})$ and 10 minutes later stopped with $30 \%$ trichloroacetic acid. Free orthophosphate (Pi) delivered from ATP hydrolysis was measured by a colorimetric assay at $660 \mathrm{~nm}$ based on the formation of a phosphomolybdate complex in an acid medium (after the addition of $3.3 \%$ ammonium molybdate in $3.8 \mathrm{~N} \mathrm{H}_{2} \mathrm{SO}_{4}$ and $10 \% \mathrm{FeSO}_{4}$ ) followed by a reduction or complexation with basic dyes that yield colored complexes $[97,98]$.

4.8. Fluidity Changes of Mitochondrial Membranes. 1,3-dipyrenylpropane (DPP) incorporation into membranes forms intramolecular excimers depending mainly on the medium microviscosity and temperature of determination [99]. Membrane fluidity is determined by estimating the excimer to monomer fluorescence intensity ratio (Ie/Im) of this fluorescent probe, a quotient that reflexes the lateral mobility of membrane phospholipids [100]. Briefly, mitochondria were resuspended in Tris- $\mathrm{HCl}$ buffer $(50 \mathrm{mM}, \mathrm{pH} 8)$ and then fragmented by sonication for 15 seconds before being separated by centrifugation at $13000 \mathrm{rpm}$. The mitochondrial membrane pellet was resuspended and proteins were measured using the Lowry method [95]. $0.1 \mathrm{mg}$ of mitochondrial proteins was mixed in a spectrofluorometric cell containing Tris- $\mathrm{HCl}(20 \mathrm{mM}, \mathrm{pH} 7.5)$. DPP solution in ethanol of spectroscopic grade was diluted $(0.02 \mathrm{mg} / \mathrm{mL})$ and mixed with membranes given a molar ratio of fluorescent probe to membrane phospholipids of $1: 1400$ and the mixtures were incubated in the darkness for 4 hours at room temperature. Fluorescence of DPP incorporated into membranes was measured at $24^{\circ} \mathrm{C}$ on a Perkin Elmer fluorescence spectrometer, LS50B. The fluorophore was excited at $329 \mathrm{~nm}$ and the monomer and excimer fluorescence intensities were read at 379 and $480 \mathrm{~nm}$, respectively.

4.9. Statistical Analysis. All data are shown as means $\pm \mathrm{SE}$ of triplicate experiments. Statistical analysis of the data for multiple comparisons was performed by two-way ANOVA 
followed by Student's $t$-tests. For a single comparison, the significance of any differences between means was determined by unpaired $t$-tests. The criterion for significance was $P<0.05$ in all statistical evaluations.

\section{References}

[1] M. R. D’Andrea, R. G. Nagele, H. Y. Wang, and D. H. S. Lee, "Consistent immunohistochemical detection of intracellular $\beta$-Amyloid42 in pyramidal neurons of Alzheimer's disease entorhinal cortex," Neuroscience Letters, vol. 333, no. 3, pp. 163-166, 2002.

[2] L. Saavedra, A. Mohamed, V. Ma, S. Kar, and E. P. De Chaves, "Internalization of $\beta$-Amyloid peptide by primary neurons in the absence of apolipoprotein E," Journal of Biological Chemistry, vol. 282, no. 49, pp. 35722-35732, 2007.

[3] K. Simons and R. Ehehalt, "Cholesterol, lipid rafts, and disease," Journal of Clinical Investigation, vol. 110, no. 5, pp. 597-603, 2002.

[4] M. O. Grimm, H. S. Grimm, A. J. Patzold et al., "Regulation of cholesterol and sphingomyelin metabolism by Amyloidbeta and presenilin," Nature Cell Biology, vol. 7, no. 11, pp. 1118-1123, 2005.

[5] J. Abad-Rodriguez, M. D. Ledesma, K. Craessaerts et al., "Neuronal membrane cholesterol loss enhances Amyloid peptide generation," Journal of Cell Biology, vol. 167, no. 5, pp. 953-960, 2004.

[6] B. Wolozin, W. Kellman, P. Ruosseau, G. G. Celesia, and G. Siegel, "Decreased prevalence of Alzheimer disease associated with 3-hydroxy-3-methyglutaryl coenzyme a reductase inhibitors," Archives of Neurology, vol. 57, no. 10, pp. 1439$1443,2000$.

[7] P. Mecocci, A. Cherubini, M. F. Beal et al., "Altered mitochondrial membrane fluidity in ad brain," Neuroscience Letters, vol. 207, no. 2, pp. 129-132, 1996.

[8] R. Resende, P. I. Moreira, T. Proença et al., "Brain oxidative stress in a triple-transgenic mouse model of Alzheimer disease," Free Radical Biology and Medicine, vol. 44, no. 12, pp. 2051-2057, 2008.

[9] S. Rosales-Corral, D. X. Tan, R. J. Reiter, M. ValdiviaVelázquez, J. P. Acosta-Martínez, and G. G. Ortiz, "Kinetics of the neuroinflammation-oxidative stress correlation in rat brain following the injection of fibrillar Amyloid- $\beta$ onto the hippocampus in vivo," Journal of Neuroimmunology, vol. 150, no. 1-2, pp. 20-28, 2004.

[10] S. M. Yatin, S. Varadarajan, C. D. Link, and D. A. Butterfield, "In vitro and in vivo oxidative stress associated with Alzheimer's Amyloid $\beta$-peptide (1-42)," Neurobiology of Aging, vol. 20, no. 3, pp. 325-342, 1999.

[11] K. C. Silva, M. A. B. Rosales, S. K. Biswas, J. B. L. De Faria, and J. M. L. De Faria, "Diabetic retinal neurodegeneration is associated with mitochondrial oxidative stress and is improved by an angiotensin receptor blocker in a model combining hypertension and diabetes," Diabetes, vol. 58, no. 6, pp. 1382-1390, 2009.

[12] K. Tońska, A. Sołyga, and E. Bartnik, "Mitochondria and aging: innocent bystanders or guilty parties?" Journal of Applied Genetics, vol. 50, no. 1, pp. 55-62, 2009.

[13] A. Jana, E. L. Hogan, and K. Pahan, "Ceramide and neurodegeneration: susceptibility of neurons and oligodendrocytes to cell damage and death," Journal of the Neurological Sciences, vol. 278 , no. 1-2, pp. 5-15, 2009.
[14] M. Michikawa, "Role of cholesterol in Amyloid cascade: cholesterol-dependent modulation of tau phosphorylation and mitochondrial function," Acta Neurologica Scandinavica, vol. 114, no. 185, pp. 21-26, 2006.

[15] R. G. Cutler, J. Kelly, K. Storie et al., "Involvement of oxidative stress-induced abnormalities in ceramide and cholesterol metabolism in brain aging and Alzheimer's disease," Proceedings of the National Academy of Sciences of the United States of America, vol. 101, no. 7, pp. 2070-2075, 2004.

[16] S. Mitew, M. T. K. Kirkcaldie, G. M. Halliday, C. E. Shepherd, J. C. Vickers, and T. C. Dickson, "Focal demyelination in Alzheimer's disease and transgenic mouse models," Acta Neuropathologica, vol. 119, no. 5, pp. 567-577, 2010.

[17] G. Bartzokis, "Alzheimer's disease as homeostatic responses to age-related myelin breakdown," Neurobiology of Aging, vol. 32, no. 8, pp. 1341-1371, 2011.

[18] C. Caspersen, N. Wang, J. Yao et al., "Mitochondrial Abeta: a potential focal point for neuronal metabolic dysfunction in Alzheimer's disease," The FASEB Journal, vol. 19, no. 14, pp. 2040-2041, 2005.

[19] J. W. Lustbader, M. Cirilli, C. Lin et al., "Abad directly links A $\beta$ to mitochondrial toxicity in Alzheimer's disease," Science, vol. 304, no. 5669, pp. 448-452, 2004.

[20] M. Manczak, T. S. Anekonda, E. Henson, B. S. Park, J. Quinn, and P. H. Reddy, "Mitochondria are a direct site of A $\beta$ accumulation in Alzheimer's disease neurons: implications for free radical generation and oxidative damage in disease progression," Human Molecular Genetics, vol. 15, no. 9, pp. 1437-1449, 2006.

[21] C. A. Hansson Petersen, N. Alikhani, H. Behbahani et al., "The Amyloid $\beta$-peptide is imported into mitochondria via the TOM import machinery and localized to mitochondrial cristae," Proceedings of the National Academy of Sciences of the United States of America, vol. 105, no. 35, pp. 13145-13150, 2008.

[22] D. De Pietri Tonelli, M. Mihailovich, A. Di Cesare, F. Codazzi, F. Grohovaz, and D. Zacchetti, "Translational regulation of BACE-1 expression in neuronal and non-neuronal cells," Nucleic Acids Research, vol. 32, no. 5, pp. 1808-1817, 2004.

[23] J. E. Maggio and P. W. Mantyh, "Brain Amyloid-a physicochemical perspective," Brain Pathology, vol. 6, no. 2, pp. 147$162,1996$.

[24] S. Rosales-Corral, D. X. Tan, R. J. Reiter et al., "Orally administered melatonin reduces oxidative stress and proinflammatory cytokines induced by Amyloid- $\beta$ peptide in rat brain: a comparative, in vivo study versus vitamin C and E," Journal of Pineal Research, vol. 35, no. 2, pp. 80-84, 2003.

[25] S. A. Rosales-Corral, D. Acuna-Castroviejo, A. Coto-Montes et al., "Alzheimer's disease: pathological mechanisms and the beneficial role of melatonin," Journal of Pineal Research, vol. 52, no. 2, pp. 167-202, 2012.

[26] A. Galano, D. X. Tan, and R. J. Reiter, "Melatonin as a natural ally against oxidative stress: a physicochemical examination," Journal of Pineal Research, vol. 51, no. 1, pp. 1-16, 2011.

[27] D. Bonnefont-Rousselot, F. Collin, D. Jore, and M. GardèsAlbert, "Reaction mechanism of melatonin oxidation by reactive oxygen species in vitro," Journal of Pineal Research, vol. 50, no. 3, pp. 328-335, 2011.

[28] J. B. Hoppe, R. L. Frozza, A. P. Horn et al., "Amyloid- $\beta$ neurotoxicity in organotypic culture is attenuated by melatonin: involvement of GSK- $3 \beta$, tau and neuroinflammation," Journal of Pineal Research, vol. 48, no. 3, pp. 230-238, 2010. 
[29] W. Dong, F. Huang, W. Fan et al., "Differential effects of melatonin on Amyloid- $\beta$ peptide 25-35-induced mitochondrial dysfunction in hippocampal neurons at different stages of culture," Journal of Pineal Research, vol. 48, no. 2, pp. 117 $125,2010$.

[30] S. Cheng, C. Ma, H. Qu, W. Fan, J. Pang, and H. He, "Differential effects of melatonin on hippocampal neurodegeneration in different aged accelerated senescence prone mouse-8," Neuro Endocrinology Letters, vol. 29, no. 1, pp. 9199, 2008.

[31] B. Caballero, I. Vega-Naredo, V. Sierra et al., "Favorable effects of a prolonged treatment with melatonin on the level of oxidative damage and neurodegeneration in senescenceaccelerated mice," Journal of Pineal Research, vol. 45, no. 3, pp. 302-311, 2008.

[32] Y. Hong, K. J. Palaksha, K. Park et al., "Melatonin plus exercise-based neurorehabilitative therapy for spinal cord injury," Journal of Pineal Research, vol. 49, no. 3, pp. 201-209, 2010.

[33] A. Espinar, A. García-Oliva, E. M. Isorna, A. Quesada, F. A. Prada, and J. M. Guerrero, "Neuroprotection by melatonin from glutamate-induced excitotoxicity during development of the cerebellum in the chick embryo," Journal of Pineal Research, vol. 28, no. 2, pp. 81-88, 2000.

[34] M. J. Jou, T. I. Peng, L. F. Hsu et al., "Visualization of melatonin's multiple mitochondrial levels of protection against mitochondrial $\mathrm{Ca}^{2+}$-mediated permeability transition and beyond in rat brain astrocytes," Journal of Pineal Research, vol. 48, no. 1, pp. 20-38, 2010.

[35] G. Paradies, G. Petrosillo, V. Paradies, R. J. Reiter, and F. M. Ruggiero, "Melatonin, cardiolipin and mitochondrial bioenergetics in health and disease," Journal of Pineal Research, vol. 48, no. 4, pp. 297-310, 2010.

[36] S. A. Andrabi, I. Sayeed, D. Siemen, G. Wolf, and T. F. Horn, "Direct inhibition of the mitochondrial permeability transition pore: a possible mechanism responsible for antiapoptotic effects of melatonin," The FASEB Journal, vol. 18, no. 7, pp. 869-871, 2004.

[37] Y. Parman, E. Battaloglu, I. Baris et al., "Clinicopathological and genetic study of early-onset demyelinating neuropathy," Brain, vol. 127, no. 11, pp. 2540-2550, 2004.

[38] N. G. N. Milton, "Role of hydrogen peroxide in the aetiology of Alzheimer's disease: implications for treatment," Drugs and Aging, vol. 21, no. 2, pp. 81-100, 2004.

[39] K. L. Campos, J. Giovanelli, and S. Kaufman, "Characteristics of the nitric oxide synthase-catalyzed conversion of arginine to $\mathrm{N}$-hydroxyarginine, the first oxygenation step in the enzymic synthesis of nitric oxide," Journal of Biological Chemistry, vol. 270, no. 4, pp. 1721-1728, 1995.

[40] M. D. Brand and D. G. Nicholls, "Assessing mitochondrial dysfunction in cells," Biochemical Journal, vol. 435, no. 2, pp. 297-312, 2011.

[41] C. Chinopoulos, A. A. Gerencser, M. Mandi et al., "Forward operation of adenine nucleotide translocase during F0F1ATPase reversal: critical role of matrix substrate-level phosphorylation," The FASEB Journal, vol. 24, no. 7, pp. 24052416, 2010.

[42] L. Lecanu, J. Greeson, and V. Papadopoulos, "Beta-Amyloid and oxidative stress jointly induce neuronal death, Amyloid deposits, gliosis, and memory impairment in the rat brain," Pharmacology, vol. 76, no. 1, pp. 19-33, 2006.

[43] J. Hardy and D. J. Selkoe, "The Amyloid hypothesis of Alzheimer's disease: progress and problems on the road to therapeutics," Science, vol. 297, no. 5580, pp. 353-356, 2002.
[44] R. H. Swerdlow and S. M. Khan, "A "mitochondrial cascade hypothesis" for sporadic Alzheimer's disease," Medical Hypotheses, vol. 63, no. 1, pp. 8-20, 2004.

[45] M. E. Clementi, S. Marini, M. Coletta, F. Orsini, B. Giardina, and F. Misiti, "A $\beta(31-35)$ and $\mathrm{A} \beta(25-35)$ fragments of Amyloid beta-protein induce cellular death through apoptotic signals: role of the redox state of methionine-35," The FEBS Letters, vol. 579, no. 13, pp. 2913-2918, 2005.

[46] X. Gao, C. Y. Zheng, L. Yang, X. C. Tang, and H. Y. Zhang, "Huperzine a protects isolated rat brain mitochondria against $\beta$-Amyloid peptide," Free Radical Biology and Medicine, vol. 46, no. 11, pp. 1454-1462, 2009.

[47] G. Aliev, D. Seyidova, B. T. Lamb et al., "Mitochondria and vascular lesions as a central target for the development of Alzheimer's disease and Alzheimer disease-like pathology in transgenic mice," Neurological Research, vol. 25, no. 6, pp. 665-674, 2003.

[48] G. Alvarez, M. Ramos, F. Ruiz, J. Satrustegui, and E. Bogonez, "Pyruvate protection against beta-Amyloid-induced neuronal death: role of mitochondrial redox state," Journal of Neuroscience Research, vol. 73, no. 2, pp. 260-269, 2003.

[49] Y. H. Chen, Y. X. Liang, L. Q. Chen et al., "Nephrotoxicity of tacrolimus and preventive effect of diltiazem: experiment with rats," National Medical Journal of China, vol. 89, no. 10, pp. 704-708, 2009.

[50] H. Lin, R. Bhatia, and R. Lal, "Amyloid beta protein forms ion channels: implications for Alzheimer's disease pathophysiology," The FASEB Journal, vol. 15, no. 13, pp. 2433-2444, 2001.

[51] L. Canevari, J. B. Clark, and T. E. Bates, "Beta-Amyloid fragment 25-35 selectively decreases complex IV activity in isolated mitochondria," The FEBS Letters, vol. 457, no. 1, pp. 131-134, 1999.

[52] J. K. Parks, T. S. Smith, P. A. Trimmer, J. P. Bennett Jr., and W. Davis Parker Jr., "Neurotoxic A $\beta$ peptides increase oxidative stress in vivo through nmda-receptor and nitricoxide-synthase mechanisms, and inhibit complex IV activity and induce a mitochondrial permeability transition in vitro," Journal of Neurochemistry, vol. 76, no. 4, pp. 1050-1056, 2001.

[53] J. J. Liang, E. T. Kimchi, K. F. Staveley-O'Carroll, and D. Tan, "Diagnostic and prognostic biomarkers in pancreatic carcinoma," International Journal of Clinical and Experimental Pathology, vol. 2, no. 1, pp. 1-10, 2009.

[54] B. F. Liu, S. Song, M. Hanson, and J. J. N. Liang, "Proteinprotein interactions involving congenital cataract T5P $\gamma \mathrm{C}$ crystallin mutant: a confocal fluorescence microscopy study," Experimental Eye Research, vol. 87, no. 6, pp. 515-520, 2008.

[55] S. Rosales-Corral, R. J. Reiter, D. X. Tan, G. G. Ortiz, and G. Lopez-Armas, "Functional aspects of redox control during neuroinflammation," Antioxidants and Redox Signaling, vol. 13, no. 2, pp. 193-247, 2010.

[56] J. Yao, R. W. Irwin, L. Zhao, J. Nilsen, R. T. Hamilton, and R. D. Brinton, "Mitochondrial bioenergetic deficit precedes Alzheimer's pathology in female mouse model of Alzheimer's disease," Proceedings of the National Academy of Sciences of the United States of America, vol. 106, no. 34, pp. 14670-14675, 2009.

[57] B. F. Liu and J. J. N. Liang, "Interaction and biophysical properties of human lens Q155* $\beta$ B2-crystallin mutant," Molecular Vision, vol. 11, pp. 321-327, 2005.

[58] P. L. Dentuto, L. Catucci, P. Cosma et al., "Effect of cyclodextrins on the physicochemical properties of chlorophyll a in 
aqueous solution," Journal of Physical Chemistry B, vol. 109, no. 3, pp. 1313-1317, 2005.

[59] W. A. Pryor, K. N. Houk, C. S. Foote et al., "Free radical biology and medicine: it's a gas, man!," American Journal of Physiology, vol. 291, no. 3, pp. R491-R511, 2006.

[60] J. E. B. McCallum, C. Y. Kuniyoshi, and C. S. Foote, "Characterization of 5-hydroxy-8-oxo-7,8-dihydroguanosine in the photosensitized oxidation of 8-oxo-7,8-dihydroguanosine and its rearrangement to spiroiminodihydantoin," Journal of the American Chemical Society, vol. 126, no. 51, pp. 1677716782, 2004.

[61] S. R. Ji, Y. Wu, and S. F. Sui, "Cholesterol is an important factor affecting the membrane insertion of $\beta$-Amyloid peptide (A $\beta 1-40)$, which may potentially inhibit the fibril formation," Journal of Biological Chemistry, vol. 277, no. 8, pp. 6273-6279, 2002.

[62] L. P. Choo-Smith, W. Garzon-Rodriguez, C. G. Glabe, and W. K. Surewicz, "Acceleration of Amyloid fibril formation by specific binding of $\mathrm{A} \beta-(1-40)$ peptide to gangliosidecontaining membrane vesicles," Journal of Biological Chemistry, vol. 272, no. 37, pp. 22987-22990, 1997.

[63] H. L. Smith, M. C. Howland, A. W. Szmodis et al., "Early stages of oxidative stress-induced membrane permeabilization: a neutron reflectometry study," Journal of the American Chemical Society, vol. 131, no. 10, pp. 3631-3638, 2009.

[64] A. Miyamoto, T. Araiso, T. Koyama, and H. Ohshika, "Membrane viscosity correlates with $\alpha 1$-adrenergic signal transduction of the aged rat cerebral cortex," Journal of Neurochemistry, vol. 55, no. 1, pp. 70-75, 1990.

[65] G. H. López, M. G. I. De Boschero, P. I. Castagnet, and N. M. Giusto, "Age-associated changes in the content and fatty acid composition of brain glycerophospholipids," Comparative Biochemistry and Physiology, vol. 112, no. 2, pp. 331-343, 1995.

[66] D. Burdick, J. Kosmoski, M. F. Knauer, and C. G. Glabe, "Preferential adsorption, internalization and resistance to degradation of the major isoform of the Alzheimer's Amyloid peptide, a $\beta 1-42$, in differentiated PC12 cells," Brain Research, vol. 746, no. 1-2, pp. 275-284, 1997.

[67] P. M. Clifford, S. Zarrabi, G. Siu et al., "A $\beta$ peptides can enter the brain through a defective blood-brain barrier and bind selectively to neurons," Brain Research, vol. 1142, no. 1, pp. 223-236, 2007.

[68] A. E. Roher, N. Weiss, T. A. Kokjohn et al., "Increased A $\beta$ peptides and reduced cholesterol and myelin proteins characterize white matter degeneration in Alzheimer's disease," Biochemistry, vol. 41, no. 37, pp. 11080-11090, 2002.

[69] G. Bartzokis, P. H. Lu, and J. Mintz, "Human brain myelination and Amyloid beta deposition in Alzheimer's disease," Alzheimer's and Dementia, vol. 3, no. 2, pp. 122-125, 2007.

[70] G. Bartzokis, P. H. Lu, D. H. Geschwind et al., "Apolipoprotein e affects both myelin breakdown and cognition: implications for age-related trajectories of decline into dementia," Biological Psychiatry, vol. 62, no. 12, pp. 1380-1387, 2007.

[71] D. T. Weldon, S. D. Rogers, J. R. Ghilardi et al., "Fibrillar beta-amyloid induces microglial phagocytosis, expression of inducible nitric oxide synthase, and loss of a select population of neurons in the rat CNS in vivo," The Journal of Neuroscience, vol. 18, no. 6, pp. 2161-2173, 1998.

[72] K. Hensley, J. M. Carney, M. P. Mattson et al., "A model for $\beta$ Amyloid aggregation and neurotoxicity based on free radical generation by the peptide: relevance to Alzheimer disease,"
Proceedings of the National Academy of Sciences of the United States of America, vol. 91, no. 8, pp. 3270-3274, 1994.

[73] S. Sharma, J. Prasanthi, E. Schommer, G. Feist, and O. Ghribi, "Hypercholesterolemia-induced $\mathrm{A} \beta$ accumulation in rabbit brain is associated with alteration in IGF-1 signaling," Neurobiology of Disease, vol. 32, no. 3, pp. 426-432, 2008.

[74] A. Papassotiropoulos, D. Lütjohann, M. Bagli et al., "Plasma 24S-hydroxycholesterol: a peripheral indicator of neuronal degeneration and potential state marker for Alzheimer's disease," Neuroreport, vol. 11, no. 9, pp. 1959-1962, 2000.

[75] Y. M. Kuo, M. R. Emmerling, C. L. Bisgaier et al., "Elevated low-density lipoprotein in Alzheimer's disease correlates with brain A $\beta$ 1-42 levels," Biochemical and Biophysical Research Communications, vol. 252, no. 3, pp. 711-715, 1998.

[76] P. B. Shelat, M. Chalimoniuk, J. H. Wang et al., "Amyloid beta peptide and NMDA induce ROS from NADPH oxidase and AA release from cytosolic phospholipase A2 in cortical neurons," Journal of Neurochemistry, vol. 106, no. 1, pp. 4555, 2008.

[77] H. Y. Yoon, S. H. Lee, S. W. Cho et al., "TAT-mediated delivery of human glutamate dehydrogenase into PC12 cells," Neurochemistry International, vol. 41, no. 1, pp. 37-42, 2002.

[78] M. J. Hsu, J. R. Sheu, C. H. Lin, M. Y. Shen, and C. Y. Hsu, "Mitochondrial mechanisms in Amyloid beta peptideinduced cerebrovascular degeneration," Biochimica et Biophysica Acta, vol. 1800, no. 3, pp. 290-296, 2010.

[79] H. Misonou, M. Morishima-Kawashima, and Y. Ihara, "Oxidative stress induces intracellular accumulation of Amyloid $\beta$ - protein $(\mathrm{A} \beta)$ in human neuroblastoma cells," Biochemistry, vol. 39, no. 23, pp. 6951-6959, 2000.

[80] N. R. Sims, M. F. Anderson, L. M. Hobbs et al., "Impairment of brain mitochondrial function by hydrogen peroxide," Molecular Brain Research, vol. 77, no. 2, pp. 176-184, 2000.

[81] R. J. Reiter, D. X. Tan, L. C. Manchester, and M. R. ElSawi, "Melatonin reduces oxidant damage and promotes mitochondrial respiration: implications for aging," Annals of the New York Academy of Sciences, vol. 959, pp. 238-250, 2002.

[82] D. X. Tan, L. C. Manchester, S. Burkhardt et al., "N1acetyl-N2-formyl-5-methoxykynuramine, a biogenic amine and melatonin metabolite, functions as a potent antioxidant," The FASEB Journal, vol. 15, no. 12, pp. 2294-2296, 2001.

[83] C. Schmidt, E. Lepsverdize, S. L. Chi et al., "Amyloid precursor protein and Amyloid $\beta$-peptide bind to ATP synthase and regulate its activity at the surface of neural cells," Molecular Psychiatry, vol. 13, no. 10, pp. 953-969, 2008.

[84] A. Lopez, J. A. Garcia, G. Escames et al., "Melatonin protects the mitochondria from oxidative damage reducing oxygen consumption, membrane potential, and superoxide anion production," Journal of Pineal Research, vol. 46, no. 2, pp. 188-198, 2009.

[85] V. Tapias, G. Escames, L.C. Lopez et al., "Melatonin and its brain metabolite $\mathrm{N}^{1}$-acetyl-5-methoxykynuramine prevent mitochondrial nitric oxide synthase induction in parkinsonian mice," Journal of Neuroscience Research, vol. 87, no. 13, pp. 3002-3010, 2009.

[86] L. C. Lopez, G. Escames, F. Ortiz, E. Ros, and D. AcunaCastroviejo, "Melatonin restores the mitochondrial production of ATP in septic mice," Neuro Endocrinology Letters, vol. 27, no. 5, pp. 623-630, 2006.

[87] J. W. Lee, Y. K. Lee, D. Y. Yuk et al., "Neuro-inflammation induced by lipopolysaccharide causes cognitive impairment 
through enhancement of beta-Amyloid generation," Journal of Neuroinflammation, vol. 5, article 37, 2008.

[88] A. C. Nulton-Persson and L. I. Szweda, "Modulation of mitochondrial function by hydrogen peroxide," Journal of Biological Chemistry, vol. 276, no. 26, pp. 23357-23361, 2001.

[89] A. Gonzalo-Ruiz, J. M. Sanz, J. Arévalo, C. Geula, and P. Gonzalo, "Amyloid beta peptide-induced cholinergic fibres loss in the cerebral cortex of the rat is modified by diet high in lipids and by age," Journal of Chemical Neuroanatomy, vol. 29, no. 1, pp. 31-48, 2005.

[90] L. Giovannelli, F. Casamenti, C. Scali, L. Bartolini, and G. Pepeu, "Differential effects of Amyloid peptides $\beta$-(1$40)$ and $\beta$-(25-35) injections into the rat nucleus basalis," Neuroscience, vol. 66, no. 4, pp. 781-792, 1995.

[91] J. J. Liang, C. L. Gu, M. L. Kacher, and C. S. Foote, "Chemistry of singlet oxygen. 45. Mechanism of the photooxidation of sulfides," Journal of the American Chemical Society, vol. 105, no. 14, pp. 4717-4721, 1983.

[92] K. Ishii, K. Nunoki, H. Murakoshi, and N. Taira, "Cloning and modulation by endothelin-1 of rat cardiac K channel," Biochemical and Biophysical Research Communications, vol. 184, no. 3, pp. 1484-1489, 1992.

[93] G. Paxinos, The Rat Nervous System, Academic Press, Sydney, Australia, 4th edition, 1984.

[94] A. Qazi, M.W. Halterman, Z. Mi, T. Zhang, and N.F. Schor, "Chopper is prodeath regardless of the effect of p75ICD on sensitivity to oxidative stress," Oxidative Medicine and Cellular Longevity, vol. 2011, Article ID 391659, 8 pages, 2011.

[95] O. H. Lowry, N. J. Rosebrough, A. L. Farr, and R. J. Randall, "Protein measurement with the folin phenol reagent," The Journal of Biological Chemistry, vol. 193, no. 1, pp. 265-275, 1951.

[96] B. Chance and G. R. Williams, "The respiratory chain and oxidative phosphorylation," Advances in Enzymology and Related Subjects of Biochemistry, vol. 17, pp. 65-134, 1956.

[97] R. Sacco, A. Giovanelli, L. Giuliano et al., "Epidemiological behaviour of perforated peptic ulcer before and after the introduction of antisecretory medical therapy. personal experience," Minerva Chirurgica, vol. 50, no. 10, pp. 871-878, 1995.

[98] F. Evangelisti, A. Baroncelli, P. Bonasoni, G. Giovanelli, and F. Ravegnani, "Differential optical absorption spectrometer for measurement of tropospheric pollutants," Applied Optics, vol. 34, no. 15, pp. 2737-2744, 1995.

[99] R. Mejia, M.C. Gomez-Eichelmann, and M.S. Fernandez, "Escherichia coli membrane fluidity as detected by excimerization of dipyrenylpropane: sensitivity to the bacterial fatty acid profile," Archives of Biochemistry and Biophysics, vol. 368, no. 1, pp. 156-160, 1999.

[100] H. J. Galla, W. Hartmann, U. Theilen, and E. Sackmann, "On two-dimensional passive random walk in lipid bilayers and fluid pathways in biomembranes," Journal of Membrane Biology, vol. 48, no. 3, pp. 215-236, 1979. 


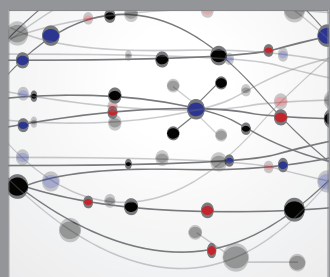

The Scientific World Journal
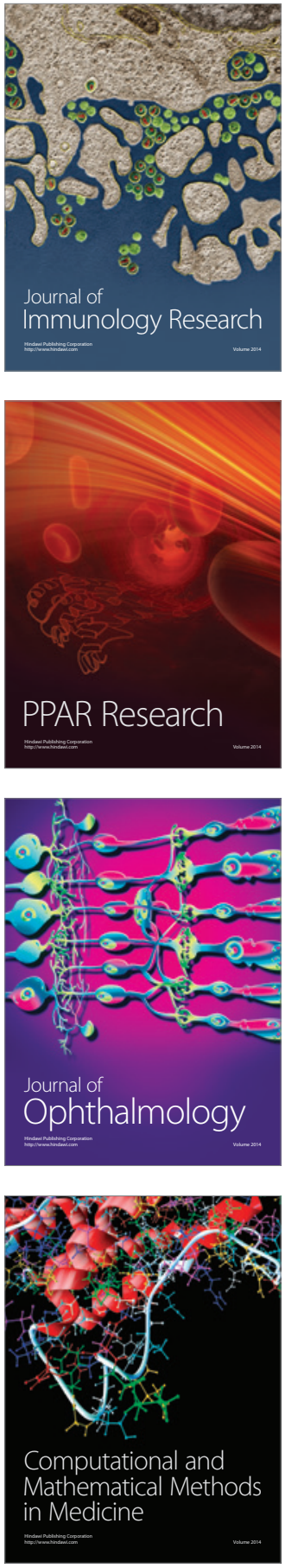

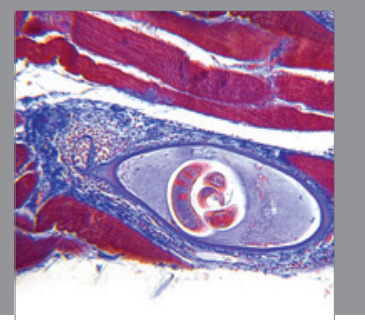

Gastroenterology

Research and Practice
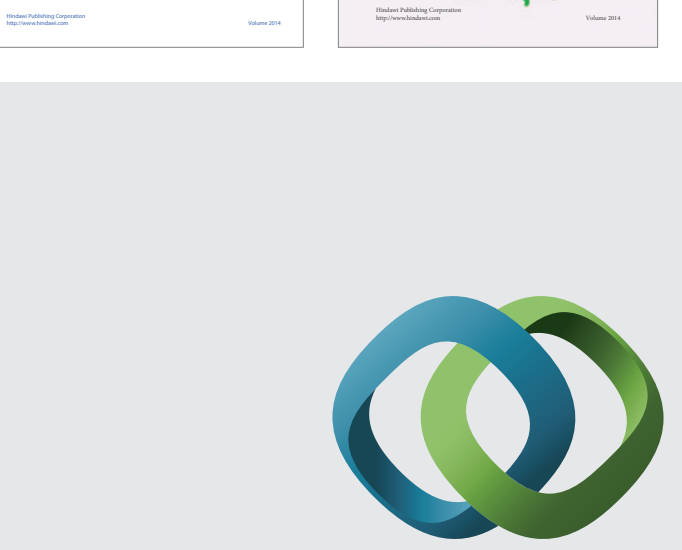

\section{Hindawi}

Submit your manuscripts at

http://www.hindawi.com
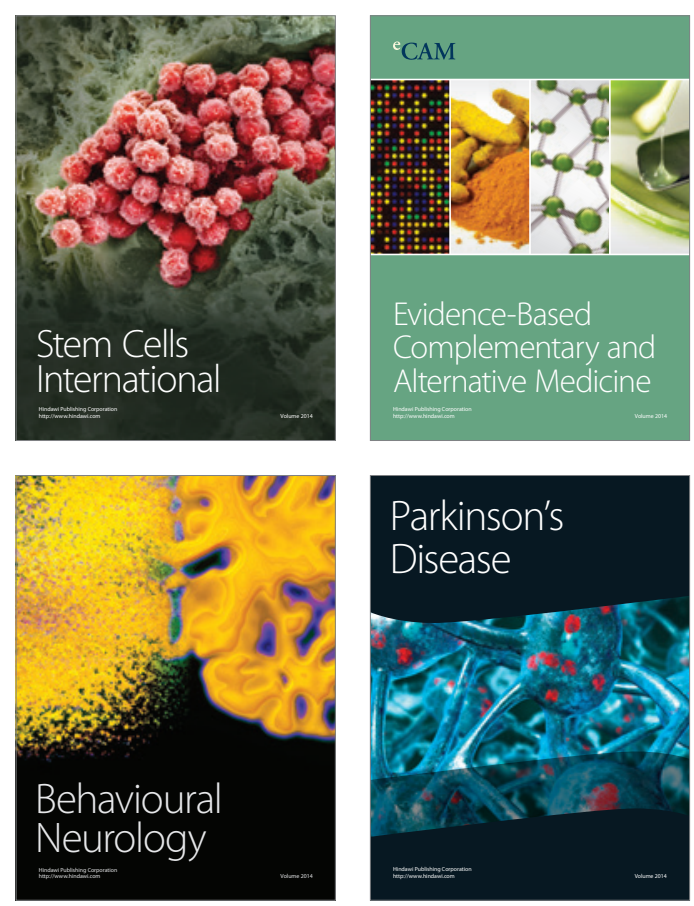

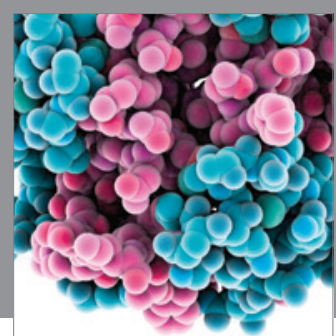

Journal of
Diabetes Research

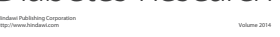

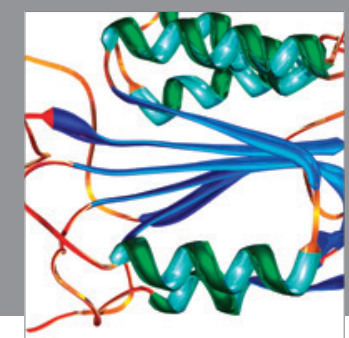

Disease Markers
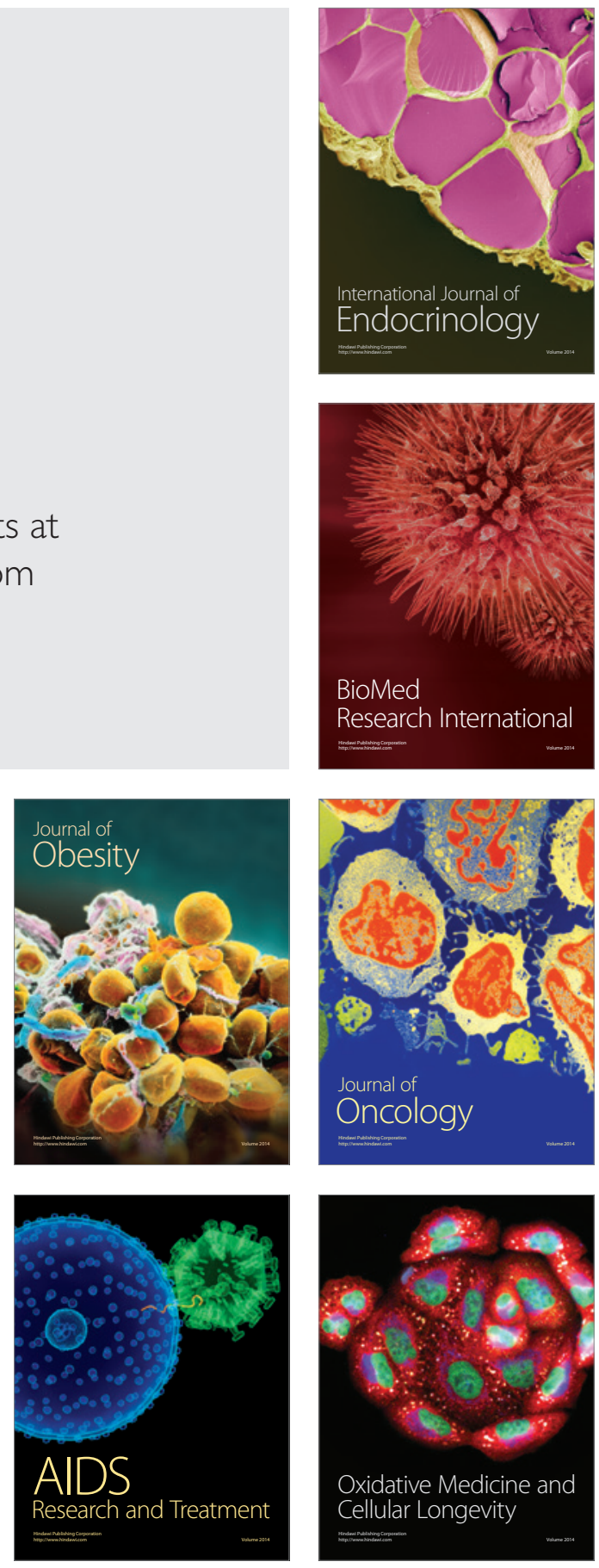